\title{
Remedial Boundary Work and Gatekeeper Centrality in a Virtual Entrepreneur Community
}

\author{
Jessica J. Santana* \\ Technology Management, University of California, Santa Barbara, Santa Barbara, CA, United States
}

OPEN ACCESS

Edited by:

Monica Thiel,

University of International Business and Economics, China

Reviewed by:

Davide Carbonai,

Federal University of Rio Grande do

Sul, Brazil

Angelo Loula

State University of Feira de Santana,

Brazil

${ }^{*}$ Correspondence:

Jessica J. Santana

jsantana@ucsb.edu

Specialty section: This article was submitted to

Organizational Psychology,

a section of the journal

Frontiers in Communication

Received: 04 August 2021

Accepted: 02 December 2021

Published: 17 January 2022

Citation:

Santana JJ (2022) Remedial Boundary Work and Gatekeeper Centrality in a

Virtual Entrepreneur Community.

Front. Commun. 6:753329.

doi: $10.3389 /$ fcomm.2021.753329
Virtual communities of practice invoke novel forms of boundary work that are newly visible via publicly recorded discourse and failure narratives. This boundary work has critical implications for occupational knowledge, membership, and stratification. Building on social exchange theorization of network gatekeeping, the author tests the assumption that centralized peers are more competitive gatekeepers, in that they react more negatively to remedial narratives. The author tests this theory using empirical data from a virtual entrepreneur community on Reddit. The author finds that a peer's tenure in the community network is directly related to exclusive, competitive boundary work of remedial members. However, by looking beyond the network structure to the content of the tie, the author finds that exclusive boundary work is not as impactful as inclusive, collaborative boundary work in this open network setting. The author builds on relational cohesion and exchange commitment theory to explain how remedial practitioners circumvent central community gatekeepers through failure narratives that provoke empathy from peripheral peers who experience higher uncertainty than core peers. Understanding these dynamics is critical to promoting recovery from failure and vitality of the community of practice.

\section{Keywords: virtual communities of practice, discursive boundary work, remedial narratives, exchange commitment, network analysis, entrepreneurship}

\section{INTRODUCTION}

"I've tried and failed two startups. I'm in no position to find a job. I'm looking for business ideas."

"Feel free to reach out to me anytime ... I would love to be a part of the project."

"This is fantastic! Yay for Reddit making connections!"

The above exchange took place among a 25-year-old electrical engineer in India, a software developer in New York, and a 59-year-old cuckoo clock designer in Georgia. The 18-min conversation was made possible by Reddit, an online discussion forum that calls itself "the front page of the internet" and "a network of communities," including the "Entrepreneur" community quoted above. Over 430 million people from around the globe are active on Reddit each month.

\footnotetext{
${ }^{1}$ The author thanks Karen Cook, Dan McFarland, Jesper Sorensen, Mark Granovetter, and Paul Leonardi for their invaluable feedback on earlier drafts of this paper. Thank you also to Kyle Lewis, who fought to give me the teaching relief to complete this paper during a global pandemic. Finally, thank you to the entrepreneurs who were willing to share their failure experiences with me.
} 
Networked learning (Powell 1990; Kogut and Zander 1996; Powell et al., 1996) is not new to organizational theory. But the virtual convergence of previously isolated communities of practice permits entrepreneurs and other practitioners to organize on a scale and at a pace never seen before (Kuhn and Galloway 2015). The factors that make virtual communities unique alter social behavior in ways that test existing organizational theory.

This study addresses the scientific problem of how remedial members in a virtual community recover lost reputation. Previous research describes virtual communities as predominantly open (c.f. Kane and Ransbotham 2016; Faraj and Johnson 2011; Shaw 2012), and boundary work as a process of closure (c.f. Freidson 1988; Lin et al., 2001, 1999; Bourdieu, 1984; Bourdieu, 1986), leaving unanswered the question of how virtual communities manage membership boundaries. Those that do explore boundary work in virtual communities tend to focus on newcomer claims to membership (c.f. Yeshua-Katz 2016; Silva et al., 2009; Lampe and Johnston 2005; Arguello et al., 2006; Choi et al., 2010; Honeycutt 2005; Kraut and Resnick 2012). It is less clear, however, how existing members of the community who have transgressed community norms regain lost reputation.

In this study, the author shows how virtual communities invoke newly visible forms of boundary work (Langley et al., 2019; Comeau-Vallée and Langley 2020) and social capital in response to remedial work, such as failure narratives. The study specifically evaluates the role of network structure as a mechanism for discursive boundary work in a virtual community of practice, where demarcations and identities are ambiguous. In this context, the resource that is gated is social capital, including community membership, network ties, and reputation. Here, the author tests the social network theory that central peers engage in more gatekeeping, hypothesizing that a peer's centrality in the community network influences the sentiment of their response to a failure narrative. The author tests this theory using empirical data from a virtual entrepreneur community on Reddit. Virtual entrepreneur communities are an ideal context for this study, because failure is common in entrepreneurship. Failed entrepreneurs must be able to recover lost reputation in order to start a new venture.

This study finds that a peer's tenure in a virtual entrepreneur community is directly related to negative, exclusionary boundary work of remedial members. However, by looking beyond the network structure to the content of the tie, the study also finds that exclusive boundary work is not as impactful as inclusive, collaborative boundary work in this open network setting. This study builds on relational cohesion and exchange commitment theory to explain how remedial practitioners circumvent central community gatekeepers through failure narratives that provoke empathy from peripheral peers who experience higher uncertainty than core peers. Understanding these dynamics is critical to promoting recovery from failure and vitality of virtual communities of practice.

\section{THEORY}

\section{Boundary Work in Virtual Communities}

"Community" is an important organizational phenomenon because they explain how organizations can create knowledge without market incentive and diffuse knowledge without hierarchy (Adler et al., 2008; see also; Lee and Cole 2003; Lave and Wenger 1991; O'Mahony and Lakhani 2011). The paradox of community, however, is that they foster "closure and insularity" that can hinder knowledge creation and diffusion (Freidson 1988). Communities, even those that are virtual, are defined by "boundary work," or the "purposeful individual and collective effort to influence the social, symbolic, material, or temporal boundaries; demarcations; and distinctions affecting groups, occupations, and organizations" (Langley et al., 2019; see also; Gieryn 1983; Schwalbe et al., 2000; Glaser 2001; Rainie and Wellman 2012; Rheingold 1993; Faraj et al., 2011; Faraj et al., 2016; Autio et al., 2013; Marquis et al., 2011; Lamont and Molnar 2002; Vaisey 2007; Tonnies and Loomis 1957). Community behavior is motivated by "belonging" to a common identity. In this perspective, community is a "category of meaningful social relationships" that is not necessarily bound by geography (Marquis et al., 2011: xii). Community members define membership by continuously negotiating community boundaries (Lamont and Molnar 2002). As social groups driven by a shared identity, communities exhibit a preference for "in-group" members over "out-group” members (Sherif 1954, 1958; Sherif et al., 1961; Tajfel and Turner 1985). Boundary work separates insiders from outsiders (Fine and Kleinman 1979; Widdicombe and Wooffitt, 1990; Becker 2008; Fine 2019). Here, boundary work is defined as the act of distancing or embracing others using language, symbols, or other mechanisms with the intention of distinguishing in-group from out-group members.

In organizational theory, boundary work has been explored most thoroughly in professional communities such as medicine and law where boundaries become clearly demarcated through explicit, controlled symbols such as certifications (Starr 1982; Abbott 1995; Lamont and Molnar 2002). In many cases, however, boundaries are ambiguous or otherwise porous. Virtual communities, for example, are unencumbered by physical gates and boundaries (Faraj et al., 2011; Jones 1998:19; Jones 1997; Rheingold 1993; Marquis et al., 2011; Sproull and Arriaga 2007; Preece et al., 2004). In place of legal or similarly authoritative boundary demarcation, these communities rely on identity-based boundary work (c.f. Lamont and Molnar 2002; Tajfel and Turner 1985; Jenkins 1996; Snow and Anderson 1987; Vaisey 2007). This raises the question of how boundary work operates in virtual communities, where demarcations and identities are nebulous.

To understand how boundary work operates in loosely demarcated communities, we must understand its motivations. Lamont and Molnar (2002) state that "Symbolic boundaries ... are an essential medium through which people acquire status and monopolize resources." Gieryn argued that it is motivated in the scientific community by the desire to "enlarge the material and 
symbolic resources of scientists or to defend professional autonomy" (Gieryn 1983:782). Community members may engage in boundary work because they wish to reinforce an existing community structure or to steer the direction of the community's future structure. Founding members of the community generally establish the community with a vision in mind and use that vision as a guiding star as the community grows (c.f. Stinchcombe (1965), or legacy, of founding context onto present-day organizations). As a community grows and diversifies, sub-communities emerge with diverging interests (c.f. Tajfel and Turner 1985; Stets and Burke 2005 for a summary of inter-group dynamics in social identity theory). Charismatic leaders in these sub-communities who are new to the community and bring a new perspective or desire more status or power may assert a new defining vision for the broader community (Weber 1921; Philips and Zuckerman 2001; Podolny 2008; Granovetter 2017).

One form of boundary work in online communities is community moderation. Moderators are community members who have the ability to decide which content is allowed according to the community standards. Ley (2007) demonstrates how exclusionary boundary work by the moderator of an online pregnancy and mothering group led to the emergence of a splinter community. Smithson et al. (2011) show how participants in an online self-harm support forum engage in the process of setting boundaries between normative and deviant behavior in concert with moderators. Yeshua-Katz (2016) describes the process through which moderators of an online fertility support forum manually filter content from newcomers as well as from established members who have successfully become pregnant.

Yet, boundary work can be normative as well as authoritative. Newcomers must learn the norms of the community they wish to join. Silva et al. (2009) observed that established members of blogging community MetaFilter "warranted" "legitimate peripheral participation" of newcomers through ignoring posts, congratulatory comments, or ridicule. Similarly, Lampe and Johnston (2005) show how established members of Slashdot "teach" newcomers community norms through rating or ignoring posts. In a text analysis of eight Usenet newsgroups, Arguello et al. (2006) found that newcomers were more likely to be ignored than established members. Choi et al. (2010) observe how, in addition to ignoring and rating posts, established members socialize new members through welcome messages, task requests, assistance, positive feedback, constructive criticism, and personal comments. Honeycutt (2005) observed elite members of the X-Filesaholics discussion forum hazing newcomers in order to increase loyalty to the group (Aronson and Mills 1959). Community leaders also use these socialization methods to screen out unhelpful or harmful newcomers (Kraut and Resnick 2012).

Boundary work is not always supportive of newcomers. Yeshua-Katz (2013) observed how established members of an online support group for people with eating disorders engaged in "blocking," hate mail, and blacklisting members who were perceived as inauthentic. This exclusionary boundary work is particularly salient in social movements where the attributes that separate insiders from outsiders is contested. Dowling et al. (2020) operationalized boundary work between GamerGate supporters and opponents using shared hyperlinks and the hashtag \#Gamergate discussion label on Twitter. Similarly, Buyukozturk et al. (2018) observe a diverse range of boundary work in the GamerGate movement on Reddit, including "offensive othering, defensive othering, boundary framing, adversarial framing, fleeing the sinking ship, internal solidarity, inciting member action, policing, rebranding, and movement space."

Boundary work can be inclusive or exclusive (Mackert 2014). One type of inclusive boundary work is membership outreach, in which an incumbent member activates a tie or builds a deeper relationship with the transgressive member to welcome them into the community. Conversely, a rejection of membership can entail an incumbent member publicly defaming the transgressive member to label them as unwelcome in the community.

\section{Remedial Narratives, Reputation, and Gatekeeping}

A variety of empirical studies have demonstrated that established, embedded, or otherwise elite members of a community engage in boundary work of newcomers. Yet, remedial members also present a case of class structuration that provokes boundary work. Remedial boundary work is distinct from newcomer boundary work because it is the process of attempting to recover social capital that has been lost. While newcomers must demonstrate that they will not fail, remedial members have indeed failed. The question is then how those remedial members can recover their reputation.

A dominant incentive for participation in virtual communities is social capital (Constant et al., 1996; Wasko and Faraj 2000; Lerner and Tirole 2002; Wasko and Faraj 2005; Faraj and Johnson 2011; Hwang et al., 2015). Lin et al. (2001) defines social capital as "investment in social relations by individuals through which they gain access to embedded resources to enhance expected returns of instrumental or expressive actions" (2001:19). One of the returns on social capital investment is reputation. Lin broadly defines reputation as "favorable/unfavorable opinions about an individual in a social network" (2001:19). Reputation is particularly important in virtual communities. Participants, by participating, have already demonstrated a motivation to belong to the community. While that motivation and the effort to belong vary by individual, the simple act of posting content strongly demonstrates value of the community and their reputation in it.

Virtual community members are not only incentivized by their community reputation, but also rely on reputational signals in their community interactions. In semi-anonymous, porous communities, legal mechanisms are not present to replace social trust (Cook and Santana 2020). In virtual communities, where members come and go freely under various identities, uncertainty is high. Members have less certain expectations of how other members will behave. Social capital is an exchangeable resource that reduces exchange uncertainty (Coleman 1990; Burt 1992; Lin 1999; Cook, 2009). Reputation is one product of social capital that reduces exchange uncertainty (Kollock 1994; Cook and Santana 2020). Network embeddedness is another form of social capital 
that reduces uncertainty (Granovetter 1985; Cook and Santana 2020). In porous, semi-anonymous communities, reputations are malleable and networks are open rather than closed. In other words, there is more uncertainty. Any available social capital is thus of premium value to exchange in this setting. In knowledge networks, reputation signals information quality (Hwang et al., 2015; Faraj et al., 2016). The value and health of the community is only as good as the information shared in it. In this context, gatekeepers aim to exclude information and informants that are misleading. Gatekeepers rely on signals of quality to discern the worthy from the unworthy. Reputation is one of few signals of quality in virtual communities.

Social capital and reputation are particularly threatened when a member of the community violates local norms. In a community of practice (Lave and Wenger 1991; Wenger 1998), these norms can be intra-professional, between community members, or extra-professional, addressing clientele or society more broadly (Abbott 1983). To remediate a violation of these norms, community members engage in remedial work. Remedial work is an expressive attempt to reaffirm membership in a community following violation of community norms (Goffman 1971). When a member admits professional failure by publishing a remedial narrative, their reputation in the community should suffer (c.f. Lakhani and von Hippel (2003); Hwang et al., 2015).

To address a failure, make sense of it, and re-assert their membership in the community, remedial members present "failure narratives" to the peer audience. Failure narratives are stories or accounts about a failure experience narrated via text, audio, or some other manner (Orbuch 1997; Cardon et al., 2011; Mantere et al., 2013; Opperman and Spencer 2016). Often, failure narratives are attempts at acknowledging and repairing a transgression, whether perceived or actual (Goffman 1971). Failure narratives may include apologies, testimonies, confessions, redirection of blame, explanations and other information or behavior required to make sense of the failure and the narrator's role in it.

Failure narratives do not guarantee remediation. Peers can reject a narrative as insufficient, inaccurate, or otherwise unacceptable (Kibler et al., 2017). Inversely, peers may embrace a narrative as honorable, representative, or otherwise contributing to the community, affirming the narrator's membership in the process. Peers can also simply acknowledge a narrative, or ignore it. These responses are all examples of peer community boundary work. Peer affirmation is a form of "social credential" (Lin et al., 2001:7) that leads to community-specific social capital, including new ties, as well as maintenance of membership in the community. Lin et al. (2001) describes this social "reinforcement:" "Being assured of one's worthiness as an individual and a member of a social group sharing similar interests and resources not only provides emotional support but also public acknowledgment of one's claim to certain resources" (2001:7). This social capital should help the remedial member to heal a damaged reputation and recover from failure. Rejection leads to unacceptance of the narrator's remedial attempt and continued ostracization of the narrator. In the case of communities of practice, this implies delegitimation of the practitioner. This leads us to ask the conditions under which a peer will respond favorably, or critically, to a remedial narrative.

\section{Centrality and Gatekeeping in Social Exchange Theory}

Given that community membership and its inherent social capital are the object of exchange, boundary work and gatekeeping can be modeled as forms of social exchange. Social exchange theory models social interactions based on expected utility gained or lost through the interaction (Berger et al., 1972; Lovaglia 1994, 1995; Thye 2000; Thye et al., 2006; Karen and Eric, 2013). In the structural view of social exchange theory, structural position directly influences power and control of resources, including social capital. Gatekeepers occupy a powerful position in that they restrict access to a valued resource. The gatekeeper concept (Lewin 1947) unites social exchange theory with boundary work when the resource that is gated is community membership and the social capital it affords, including status and network ties (c.f. Gould and Fernandez 1989; Hamann and Beljean 2019; Merton 1973).

One's location in a social network is "the key element" of social capital functions (Lin et al., 2001:13), including reputational recovery from failure. Cook (1983) described centrality as "one of the most important characteristics of positions" in social networks (p. 283). Social exchange theory suggests that centrality may motivate boundary work (c.f. Corra and Willer 2002; Burt 1992; Granovetter 2017). A boundary worker can be more or less connected to other community members, and this variance may influence the valence of ties between boundary workers and their targets. Centrality can be associated with structural or non-structural properties. If a community is defined by interactions, centrality describes a member's engagement with the community. More concretely, highly central members interact with a larger proportion of the community than less connected members. Centrality entails significant advantages for community members. Connected members have more access to higher quality information, are less dependent on a single relationship, may be able to control resource access, and are more likely to be connected to other highly connected members (Cook and Emerson 1978; Granovetter 1985; Burt 1992; Uzzi 1999; Podolny 2008). This means that central members are generally more influential, more powerful, more popular, have more status, and are more successful in related endeavors (Bonacich 1987; Walker et al., 2000; Sutanto et al., 2011; Johnson et al., 2015).

Centrality renders two important attributes that facilitate gatekeeping: incumbency and influence. First, as members become more established, tenured, and connected, they become more central. Safadi et al. (2020) found that core members play a key role in the sustainability of the community and in its knowledge production. These members tend to take on leadership roles in their 
community (O'Mahony and Ferraro 2007; Johnson et al., 2015). More established members also contribute more content than newer members (Kane and Ransbotham 2016). These incumbent members tend towards homophilic preference for similar members with similar values. Network closure promotes preservation of the status quo (Bourdieu, 1986; Lin et al., 2001). Those who enter the highly connected core of the community are members with similar preferences, similar values, and similar motivations. This homophily feeds the maintenance of the status quo in the community. Members who deviate from status quo norms face criticism by those who value the status quo. As privileged and committed members of the community, these core members are more likely to defend the status quo norms of the community. In a study of an online blogging community, Silva et al. (2009) show how established community members "ridicule and even insult newcomers who they felt deviated from the expected ways of making a contribution." This boundary work was more recently visible following the GameStop "short squeeze" of January 2021, where incumbent Reddit forum "wallstreetbets" users asked moderators to ban new members to the forum in order to retain the forum's former professionalism (Shifflett 2001). The quality of the community is important to those who established the community and regularly contribute to it.

Second, central community members enjoy structural positions of power. Network centrality can be a proxy (or mechanism) of status (Podolny 2008; Granovetter 2017). Wasko and Faraj (2005) found that the closeness centrality of members on Stack Exchange was positively associated with higher ratings of that member's posts, meaning that core members were perceived as providing higher value contributions. Core online community members contribute more valuable knowledge and status, as perceived by other members (Safadi et al., 2020). Central actors have more network ties to exchange and community status. This status discourages central members from deviating from the status quo in which they have prospered. From the social exchange theory perspective, gatekeeping is an ability of those actors with "structural power" (Schaefer and Kornienko 2009) or "positional advantage" in a network to control resource flow, meaning that others in the network are dependent on them. In this view, network exchanges accumulate to central actors on whom the network is most dependent (Cook 1977; Cook and Emerson 1978; Cook, 1983; Markovsky et al., 1988; Thye et al., 1997; Schaefer 2011).

\section{THEORETICAL PROPOSITION}

Centrality renders incumbency and influence, which positions central members as potential community gatekeepers. Prior research has demonstrated that central members engage in boundary work of newcomers. Because remedial members have violated the norms that central community members value, central members should engage in boundary work of remedial members. This dynamic is heightened in a virtual community, where members rely on reputational signals to interact with semianonymous members.

This study looks specifically at the relationship between peer centrality in a virtual community network, where community membership and social capital are exchangeable resources, and where interactions are discursive, and peer boundary work in response to a remedial narrative. Assuming, in this context, that boundary work ranges from negative (peer rejection) to positive (peer affirmation), this study tests the following hypothesis:

H1. Members that are more central in the virtual community will reject remedial narratives more often than less central members.

This expected relationship is modeled in Figure $\mathbf{1}$ below. A failure event of individual $i$ in domain $\mathrm{m}$ reduces individual i's reputation in domain $\mathrm{m}$. Following the failure, individual $\mathrm{i}$ decides whether or not to present a failure narrative to a community $\mathrm{c}$ associated with domain $\mathrm{m}$. This failure narrative influences individual i's membership in community $c$ in the following manner. If peers in community $c$ respond to the failure narrative by affirming, or maintaining, individual i's membership, then individual $i$ will gain access to new social capital in community c (e.g., introductions to employees/ investors/clients/partners) that will improve individual i's reputation in domain $\mathrm{m}$. Hypothesis 1 states that the centrality of peer $\mathrm{j}$ in community $\mathrm{c}$ negatively moderates peer j's likelihood of affirming, or maintaining, individual i's membership in community c. By not affirming membership, peer $j$ blocks individual $i$ from access to social capital in community c. This is an instance of gatekeeping, where the decision of "peer affirmation" is the gateway to vital social capital, including "social credentials" and "reinforcement" (Lin et al., 2001:7).

\section{RESEARCH SETTING}

To test this hypothesis, the author empirically analyzes the relationship between peer centrality and response to failure narratives in $\mathrm{r} /$ Entrepreneur, a virtual community of global entrepreneurs on Reddit. Virtual entrepreneur communities are groups of entrepreneurs that interact via virtual technology such as a website. These communities are field sites in which behavioral data is collected at a level of detail and scale found nowhere else (Parigi et al., 2017). Through virtual entrepreneur communities on platforms like Reddit, we can observe both remedial discursive boundary work and network structure.

An entrepreneurial virtual community is an ideal research setting for this study because entrepreneurship exhibits high rates of failure and remedial work to recover lost reputation. Entrepreneurship is a context rife with failure narratives as well as discursive boundary work. As depicted in the quote introducing this paper, entrepreneurs turn to their peers to make sense of, recover from, and avoid failure. Peers can respond with support or criticism. Extreme examples of 


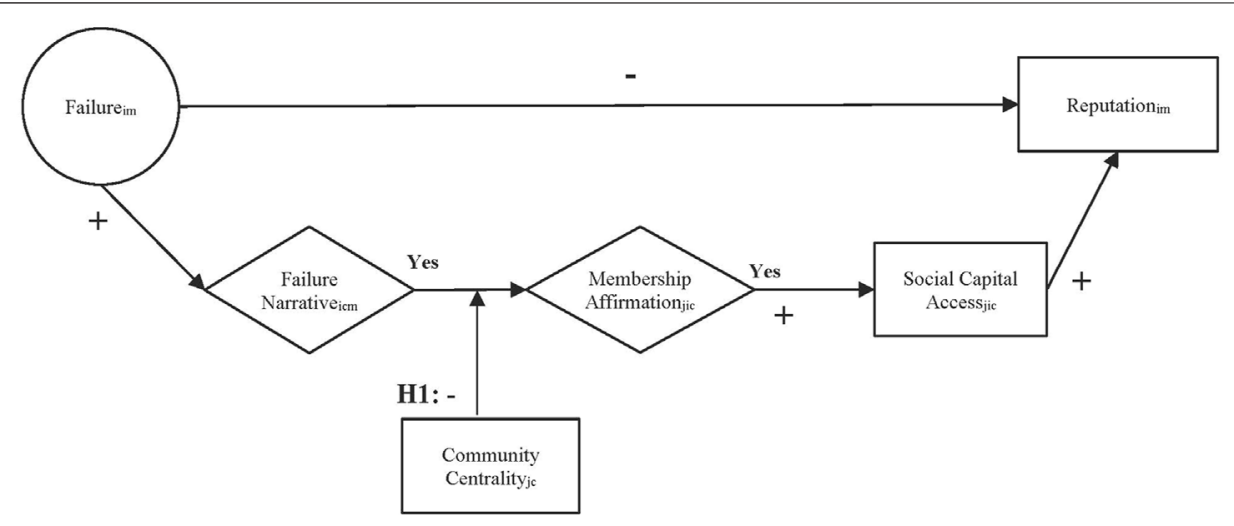

FIGURE 1 | Centralized Gatekeeping of Peer Affirmation of Community Membership as Exclusionary Remedial Boundary Work. Circles are events. Diamonds are decisions. Rectangles are resources. A failure event of individual $\mathrm{i}$ in domain $\mathrm{m}$ reduces individual i's reputation in domain $\mathrm{m}$. Following the failure, individual $\mathrm{i}$ decides whether or not to present a failure narrative to a community $\mathrm{c}$ associated with domain $\mathrm{m}$. This failure narrative influences individual i's membership in community $\mathrm{c}$ in the following manner. If peers in community c respond to the failure narrative by affirming, or maintaining, individual i's membership, then individual i will gain access to new social capital in community c (e.g., introductions to employees/investors/clients/partners) that will improve individual i's reputation in domain $\mathrm{m}$. Hypothesis 1 states that the centrality of peer j in community c negatively moderates peer j's likelihood of affirming, or maintaining, individual i from access to social capital in community c. This is an instance of gatekeeping.

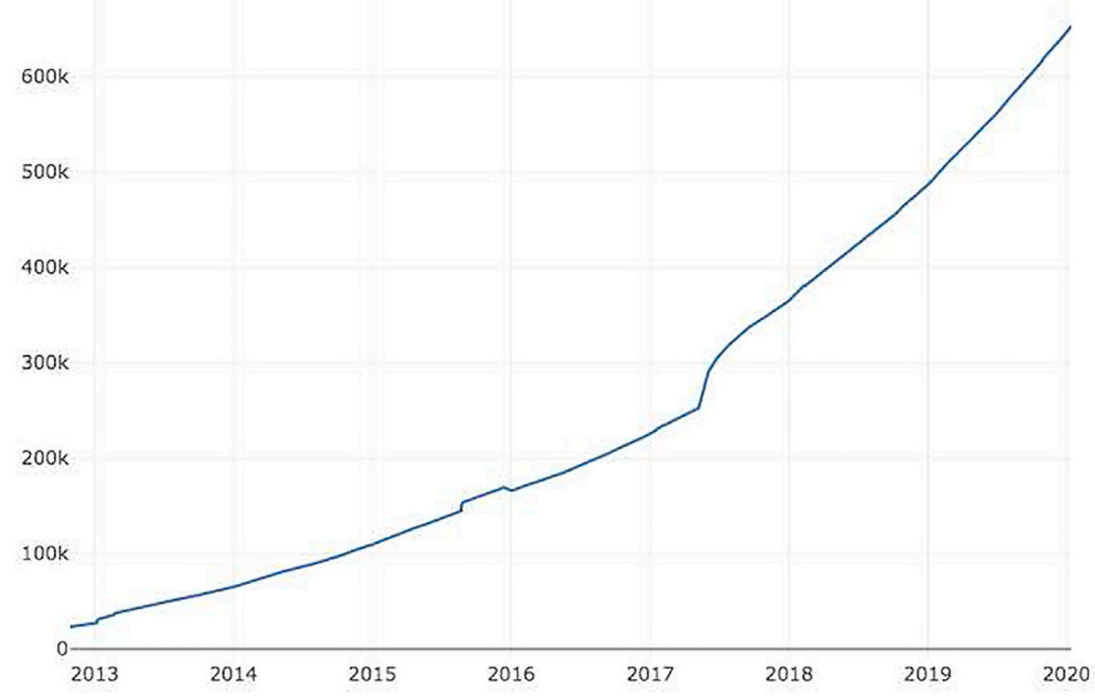

FIGURE 2 | Number Subscribers to/r/Entrepreneur Subreddit.

support include outreach for further interaction- "let's meet up," for example. And extreme examples of criticism include delegitimization of the author's identification as an entrepreneur-"you had no business starting a company," for example.

Entrepreneurship is a particularly interesting context for the study of peer community boundary work because such communities of peer entrepreneurs are informal communities of practice in which discourse-based boundary work fills the gap of legal or otherwise explicit demarcation. Unlike medicine or law, entrepreneurship does not rely on certifications to differentiate members from non-members of the profession. A teenager working on an idea in her parents' garage can call herself an entrepreneur without legal ramifications. Yet, boundary work does occur among entrepreneurs. Discursive boundary work can be observed and analyzed in virtual entrepreneur communities in which interactions are recorded and archived as "digital footprints" of the social phenomenon of interest (Golder and Macy 2014). This study analyzes the r/Entrepreneur community on the Reddit platform.

\section{The r/Entrepreneur Virtual Community of Practice}

In contrast to more geographically restricted online entrepreneurial forums like Hacker News, Reddit is an 
internationally popular platform for discussions in any language. Composed of approximately 357,000 members at the time of study (see Figure 2), the r/Entrepreneur community describes its purpose as "giving and receiving advice on all aspects of Entrepreneurship. Help and encourage each other, it's hard enough out there!"2. The forum regularly posts comments on topics including "Accomplishments and Lessons Learned," "NooB" basic questions, startup jobs or internships, and product discounts. The first discussion thread was posted to the subreddit on August 21, 2008 with the comment "I hope that this subreddit brings together entrepreneurs who are interested in learning and partnering for new startups"3. Over 170,000 discussion threads have been posted to the forum since then. The r/Entrepreneur subreddit is a virtual community of practice, with a membership comprised of people identifying as "entrepreneurs." This community is porous - anyone can post a comment in the forum. The community is also semi-anonymous, as participants are identified by "usernames" instead of legal names.

\section{DATA AND VARIABLES}

Because Reddit currently limits scraping of its content via the Reddit API to a small, recent subset of discussions, this study relies on a pre-existing database of all Reddit comments that was collected and published on Google BigQuery by Jason Michael Baumgartner of Pushshift. io and Felipe Hoffa of Google BigQuery. From this database, the author exports all comments published on the/r/Entrepreneur subreddit before January 2017, including comment text, author, parent post, and timestamp. From this unprocessed comment data, the author creates conversational edgelists where the post author is the target and the comment author is the source. The author then processes the parent post data by removing whitespaces such as tabs and new lines, transforming text to lower capitalization, and reducing words to their word stem using Porter's stemming algorithm (Porter 1980). Using text mining algorithms that dissect documents into "term-document frequencies," or matrices of term frequency per document, the author identifies which posts use the stemmed term "fail" and are thus likely to be failure narratives. The validity of these posts as "failure narratives" is verified by viewing a random subset. The analysis of comments is restricted to these 1,408 fail posts ( $1.81 \%$ of all discussion threads in the dataset). Network attributes, however, are derived from the entire subreddit (77,710 unique threads).

\section{Dependent Variable: Discursive Boundary Work}

The construct of interest for this study is boundary work. Boundary work is the "discursive attribution of selected qualities to (a social category, their methods, and their claims)

${ }^{2}$ Reddit (2017). https://www.reddit.com/r/Entrepreneur/comments/74n42/ welcome_to_the_entrepreneur_sub_reddit/.

${ }^{3}$ Reddit $2017 \mathrm{a}$ (n.d.). https://www.reddit.com/r/Entrepreneur/. for the purpose of drawing a rhetorical boundary between (that category) and some less authoritative residual (non-category) (Gieryn p. 4-5). Put otherwise, boundary work is the public contestation of credibility (Gieryn p. 4). One indicator of such public contestation of credibility are sentimental expressions of approval and disapproval of the failure narrative. People tend to express more positive sentiments toward in-group than outgroup members (Tajfel and Turner 1985). Based on assumptions of symmetry from structural balance theory (Heider 1946; Cartwright and Harary 1956), the sentiment of a dyad's discourse should reflect the sentiment of their relationship (c.f. West et al., 2014). In other words, the sentiment of a comment responding to a failure narrative post likely indicates acceptance or rejection of the failure narrative.

This study measures sentiment of comments using sentiment analysis (c.f. Wicke and Bolognesi 2021; Wang et al., 2021; Oz et al., 2018). The author compares the frequency of positive and negative terms in the comment against pre-existing dictionaries of terms associated with positive and negative sentiment (namely, the Quantitative Discourse Analysis Package, or QDAP, dictionary (Rinker 2020)). Words are not stemmed in this case, since this can alter the interpretation of sentiment ${ }^{4}$. By measuring sentiment by term frequency, this study measures the proportionality of positive and negative sentiment in each comment of the dataset. By using a continuous measure of sentiment, this study captures gradients of sentiment that are especially important given that the majority of responses in this dataset exhibit a positive QDAP score. Moreover, a continuous measure of sentiment more accurately reflects the nuances of human sentiment. As you can see in Table $\mathbf{1}$ and Figure 3 below, messages skew positive.

\section{Independent Variable: Community Network Centrality}

While online communities may have more ambiguous demarcations and exchange less tangible resources, they are observable via their interaction networks. A community of practice is often dispersed geographically and increasingly connected through online discussion forums. The public virtual forum is distinct from other types of social interaction, such as a closed office meeting, in that it is open to anyone and centrally visible. This structure has a distinct influence on community membership because, while interpersonal remediation builds relationships person-by-person, public remediation addresses the question of membership in the community at large.

The virtual public forum is an environment for interactions within the community. For large-scale communities, like those online, interactions are siloed. This is akin to classroom seminars across a large university campus. Most students are unaware of who participates more often in a given classroom discussion unless they are present in the class. Without accounting

${ }^{4}$ Potts, C (2011). http://sentiment.christopherpotts.net/stemming.html. 
TABLE 1 | Summary statistics of model variables.

\begin{tabular}{|c|c|c|c|c|c|}
\hline Variable & Mean & Std. Dev & Min & Max & $\mathbf{N}$ \\
\hline SentimentQDAP & 0.1025 & 0.1561 & -0.5 & 1 & 1,408 \\
\hline Degree & 8.497 & 29.447 & 1 & 3,176 & 74,021 \\
\hline Betweenness & $99,907.20$ & $1,028,229.96$ & 0 & $100,994,598$ & 74,021 \\
\hline Tenure+ & 12/18/2014@ 1:33pm & $43,911,895.23^{\star}$ & 08/21/2008@11:00pm & 12/31/2016@11:49pm & 74,021 \\
\hline Author Degreê & 56.19 & 91.52 & 2 & 702 & 180 \\
\hline Author Tenuret & 08/26/2014@12:21am & $47,472,439.40^{\star}$ & 07/29/2009@11:20pm & 12/27/2016@4:46am & 180 \\
\hline Initiating Post Sentiment & -0.13 & 0.21 & -1.00 & 0.33 & 185 \\
\hline Commenter Sentiment Profilê & 0.12 & 0.09 & -0.33 & 1.00 & 1,281 \\
\hline
\end{tabular}

Note: Excludes "Automoderator" bot. +Measured as timestamp of first comment, UTC, in Unix Epoch Time. *Unix Epoch Time, or seconds since Jan 01, 1970 (UTC). From observations containing the stemmed term "fail". Lagged mean.

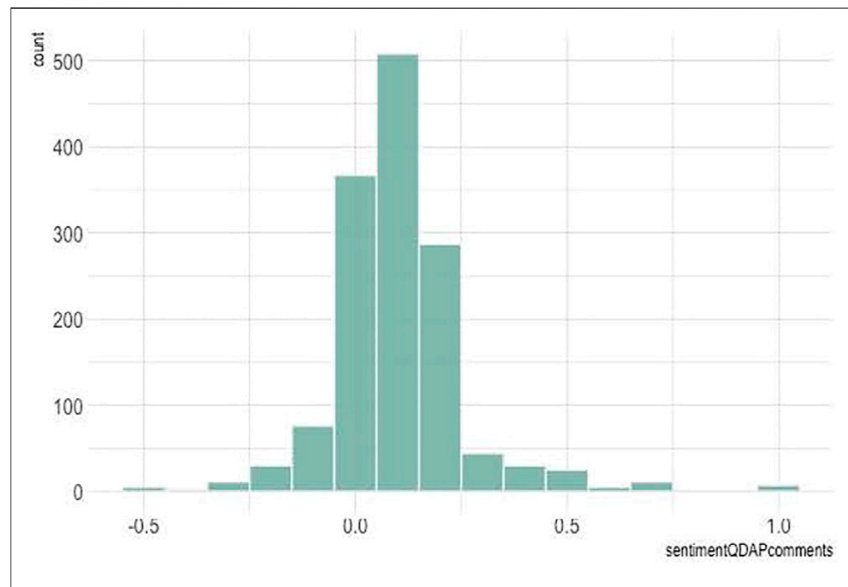

FIGURE 3 | Histogram of/r/Entrepreneur Message Sentiment.

for the nested structure here, a student who participates often in a single class, but in very few other classes, will have a similar degree centrality to a student that participates infrequently in any given class but does so across many classes. Thus, connectedness in such a community is more strongly reflected in cross-event, or cross-discussion, centrality.

If we think of the public forum as the intersection of many social circles rather than just one, we become interested in who intersects which circles. Discussions become events in which these circles are variantly represented. The well-to-do attend one set of discussion, the subversives another, and the intersections of these circles can make a discussion an explosive event not to miss. A common example of such affiliation networks is Davis et al. (1941) analysis of social event attendance by upper class women in the South. Using the society pages of local newspapers, the authors map which women attended which parties. The result is an affiliation network of parties and attendees (Borgatti and Halgin 2014). Transitive ties connect attendees into social circles or cliques, and highlight divisions within the community. In this affiliation network, member behavior is based on groups or cliques, where status and norms guide interactions.

In the case of affiliation networks, centrality is the number of events attended by attendees, or, in this study, the number of

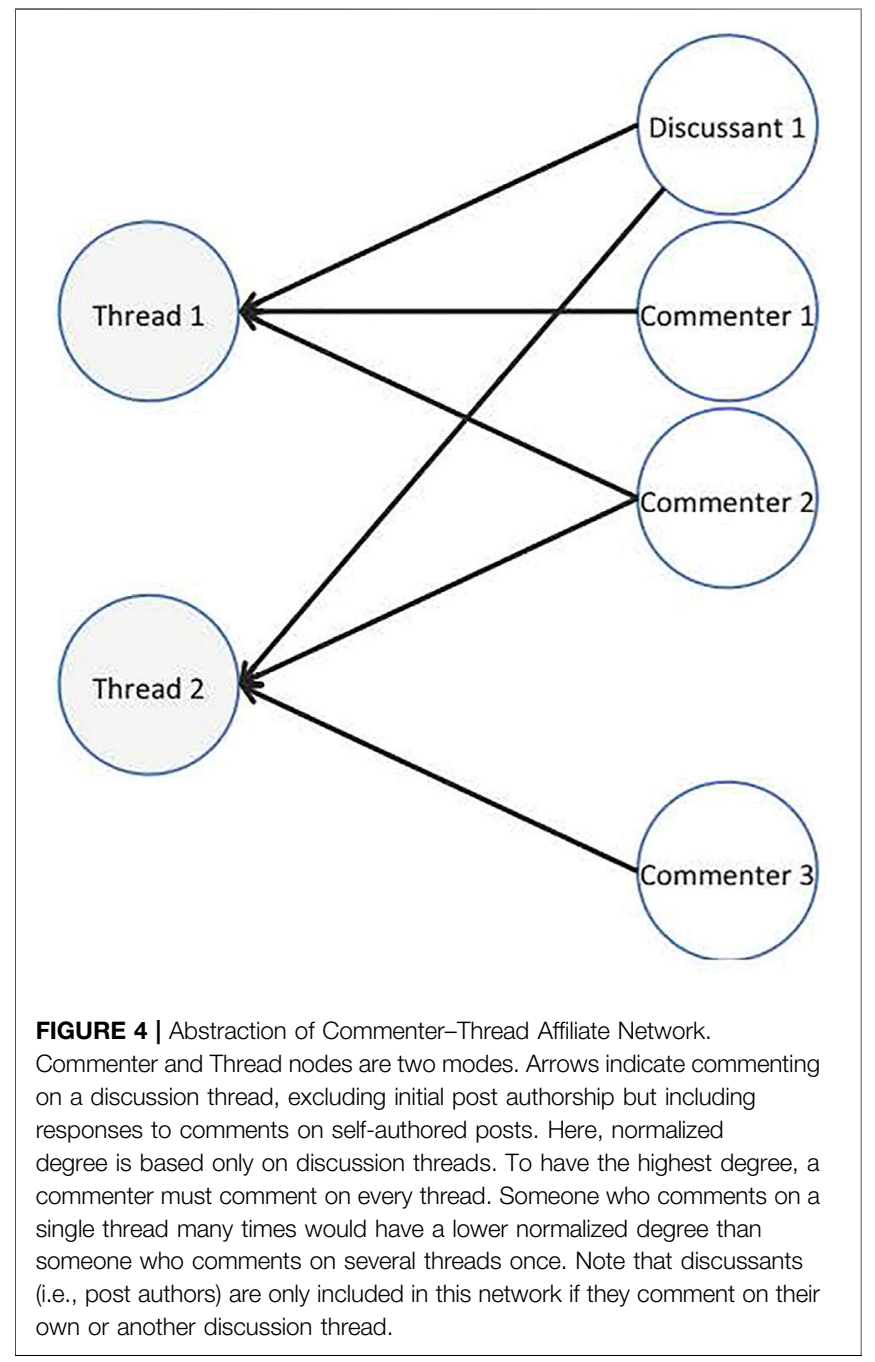

commenters "attending" a given discussion thread "event." The directed edges of the network are defined by the action of commenting on a thread, where the inbound set of nodes are the posts initiating a thread and the outbound set of nodes are people commenting on the post. The thread is thus encapsulated in the original post node and the edges to commenter nodes. This network is visually abstracted in Figure 4 below. 


\section{Scatterplot of Commenter Tenure \& Sentiment of Response to Failure Narrative}

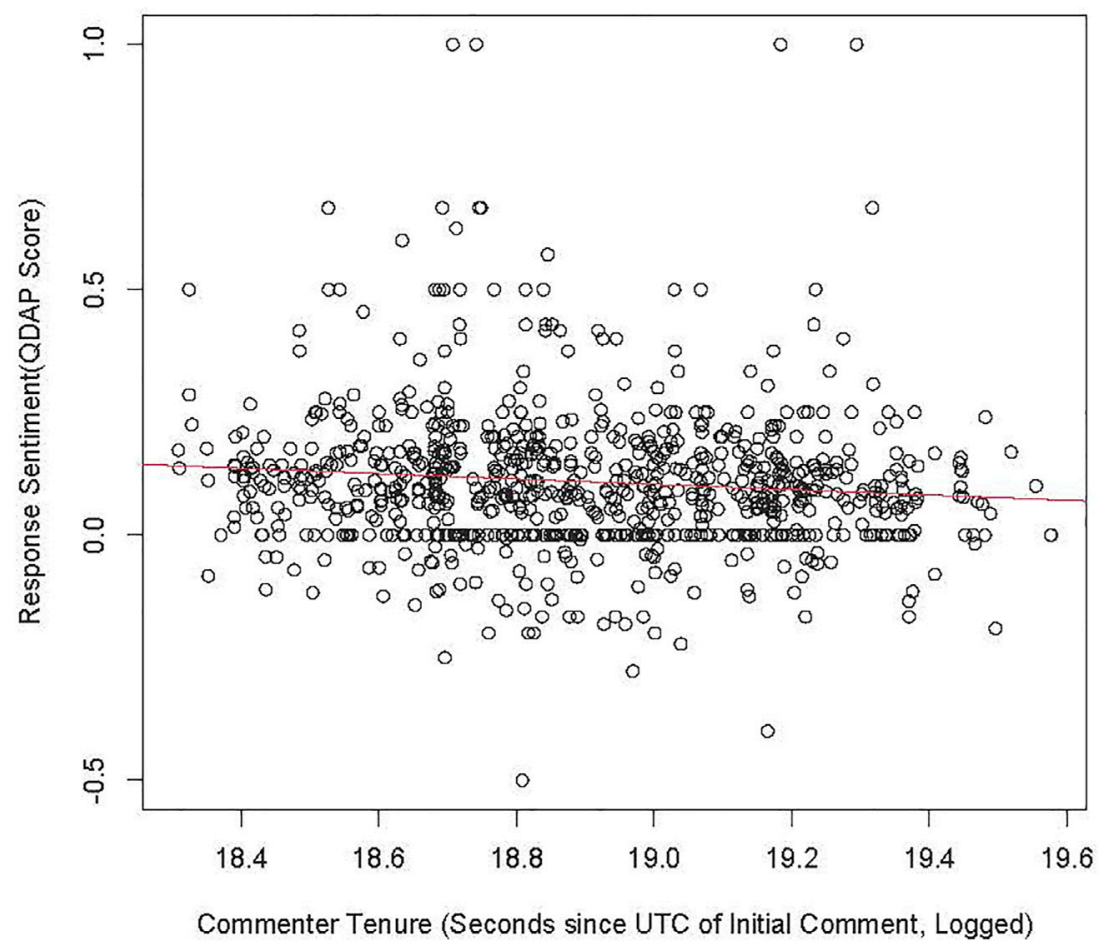

FIGURE 5 | Normalized degree distribution for commenters (by threads), log transformed.

There are many ways to measure network centrality, each indicating a different type of connectedness (Oldham et al., 2019). The simplest measure of local connectedness is degree centrality. Degree centrality is simply the number of edges leading from or to a node in a network. In our context, degree centrality measures the number of comments written on a discussion thread. To account for the bipartite structure of our network, commenter degree centrality is normalized by thread (Borgatti and Halgin 2014):

$$
a^{*}=\frac{a}{n}
$$

Where $\mathrm{a}=$ commenter-to-thread degree centrality, and $\mathrm{n}=$ number unique threads.

More than one degree indicates that a commenter has participated in more than one discussion thread. High threadnormalized degree means the member comments on many threads. As seen in the figure below, the distribution of thread-normalized degree in the "failure narrative" subset follows the typical power law found in most social networks (Albert and Barabasi 2002, see Broido and Clauset 2018 for exception), with a non-linear distribution for threads.

Most measures of centrality are collinear (Oldham et al., 2019). Oldham et al., 2019 find that the correlation of centrality measures is primarily based on the modularity of a network. In the event that the peer community is modular, meaning that it is composed of "walled gardens," or sub-communities that do not necessarily communicate with each other, global (communitywide) centrality becomes more likely to vary from local centrality measures. In such a case, global centrality measures, in contrast to local centrality measures such as degree centrality, better reflect community connectedness. The graph exhibits a modularity score of 0.519 (out of a range between $-1:+1$ ). This means that inter-module centrality is likely to vary from intramodule (i.e., degree) centrality. To measure inter-module connectedness, this study uses betweenness centrality.

Betweenness measures the number of shortest paths going through the node, i.e. the number of times the node bridges two other nodes (Freeman 1979). In the bipartite network of threads and commenters, betweenness measures shortest paths between threads as well as commenters. In other words, a commenter with a high betweenness may connect multiple threads or multiple commenters. High commenter betweenness in this bipartite graph indicates either a commenter commenting on a large proportion of threads in the graph or a commenter commenting on a thread that receives comments from a large proportion of commenters in the graph. For graphs with high modularity (i.e., many sub-communities), betweenness is a good measure of inter-module engagement.

Using Clauset et al.'s (2004) fast greedy community detection algorithm, this study finds that the commenter-thread network contains at least 3,435 sub-communities. One risk with the 
Clauset algorithm is that it might settle on a local rather than global maximum. Moreover, because this commenter-thread network is a disconnected graph (White and Harary 2001), graph-level measures of centrality, such as closeness (Freeman 1979), may not be informative (Cornwell 2005). The author thus supplements graph measures of centrality with tenure in the subreddit. Tenure is based on the date of the commenter's first comment in the subreddit.

The directed network of/r/Entrepreneur commenters and threads is summarized in Table 1. There are 476,738 comments in this dataset, which define the edges in the network. In this two-mode affiliate network, there are 174,913 nodes, of which 74,021 are unique commenters (excluding the Automoderator bot) and 77,710 are unique threads. An edge is created in the affiliate network when a commenter comments on a discussion thread.

\section{Controls}

In the r/Entrepreneur online community, typical confounding demographic variables such as race and gender are not explicitly present. Instead, the author controls for structural and interactional factors that might influence the results, including the degree centrality of the discussant (the person creating the discussion thread), the tenure of the discussant, the sentiment of the original post, and the mean sentiment of the commenter.

It is possible that the connectedness of the discussant, i.e., their status within the network, influences boundary work. A higher status discussant might demand more authority and respect in the community. The tenure of the discussant captures founder effects, in which founders of the community are treated or behave differently than neophytes. Like connectedness, a higher tenure discussant should demand respect.

The author also controls for the sentiment of the original post. It is likely that the sentiment of the post that initiates the discussion thread sets the tone for the discussion.

Finally, the study controls for the mean sentiment of the commenter as a measure of the commenter's sentiment profile. This measure is the average sentiment score of all the commenter's comments excluding the current comment (i.e., lagged).

\section{ANALYSIS}

To test the hypothesis, the author regresses the sentiment score (using QDAP dictionary) of the comment on the commenter's 1) thread-normalized degree centrality as a measure of local module-specific connectedness, and 2) betweenness centrality and tenure as measures of global cross-community embeddedness. These measures of centrality should be inversely correlated with sentiment. Because the dependent variable is a continuous value between -1 and 1 , the study uses an ordinary least squares regression model. In order to isolate the analysis to the failure narratives where boundary work should be salient, the observations are restricted to the 1,408 comments responding to posts that include the stemmed term "fail." The author log transforms the network values to account for their skewed distribution, and therefore restrict the analysis to those observations with centrality values greater than zero. Of the 1,408 comments to the 185 unique failure narratives, 576 (41\%) have a betweenness value of 0 . To include these isolated commenters in the analysis, the author uses the unlogged value of betweenness. The "AutoModerator," an automated bot that is programmed to respond to comments that transgress community rules, such as posting spam, is excluded from the analysis. In order to include the commenter's mean sentiment as a control, the analysis is restricted to commenters who have commented on at least two threads. Finally, observations with missing data are excluded (403 total, or $22 \%$ of failure narratives, excluded). The author uses clustered standard errors around discussion threads, given that many variable values will be interdependent at the thread level.

\section{FINDINGS}

\section{Results}

The results of the analysis are summarized in Table 2 and Table 3. Robust standard errors are used to obtain unbiased standard errors under heteroskedasticity. Model 1 measures only the relationship between a commenter's thread-normalized degree centrality and the sentiment of the commenter's response to failure narratives. As hypothesized in $\mathrm{H} 1$, the normalized degree of the commenter is negatively related to comment sentiment. This relationship becomes statistically insignificant after including global measures of connectedness.

Model 2 includes two global measures of embeddedness: commenter betweenness centrality and tenure in the network. These results also support $\mathrm{H} 1$, indicating that a commenter's tenure (seconds since their initial comment in the network) has a negative relationship to their response to a failure narrative. This means that for a $10 \%$ increase in seconds of the commenter's tenure (i.e., current date minus date of their initial comment), their next comment should have a lower sentiment score by approximately $-0.051 \times \log (1.1)$ or -0.002 points. In other words, the older the commenter's tenure is in the community, the more negative their response to the failure narrative is likely to be. This relationship is visualized in Figure 5 below. In Model 2, betweenness is slightly negatively associated with message sentiment, but this relationship is not statistically significant and approaches zero.

Among the included controls, the strongest predictor of comment sentiment in the model is the commenter's sentiment profile, or mean sentiment of all their prior comments. Model 3 shows that, for each increase in the commenter's average sentiment profile, the commenter's next comment should have a higher sentiment score by an average of 0.481 points. Given that comment sentiment scores in the dataset have a standard deviation of 0.156 , this increment would be significant. However, even with the inclusion of these controls, the negative relationship of commenter tenure remains statistically significant $(p=0.013)$.

\section{The Strength of Peripheral Ties}

Findings from the analysis of the r/Entrepreneur subreddit community support the hypothesis that connectedness is 
TABLE 2 | Model predicting message sentiment (QDAP dictionary frequency score).

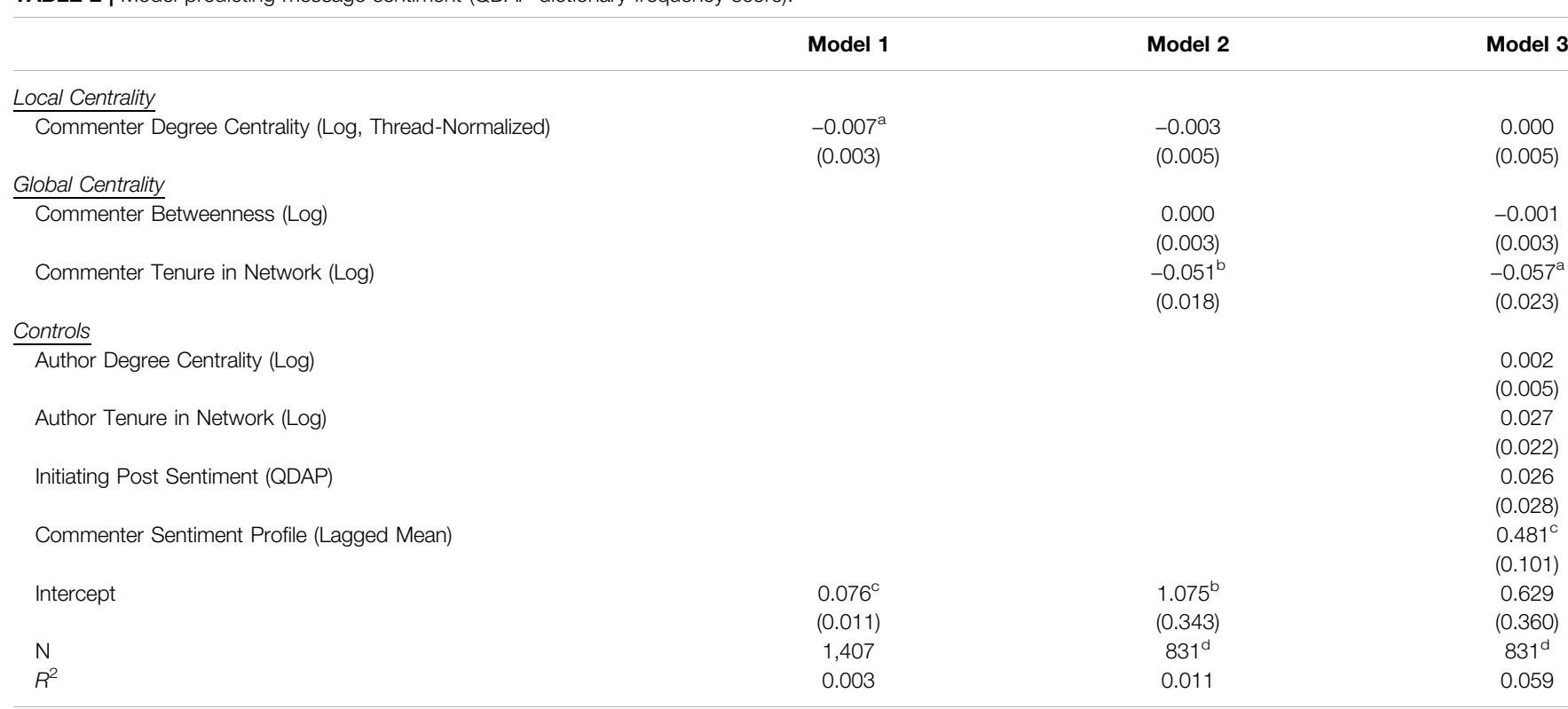

Note: Robust standard errors (in parentheses) clustered at discussion thread level. N excludes comments from "Automoderator" bot.

${ }^{a} \mathrm{p}<.05$.

${ }^{b} \mathrm{p}<.01$

${ }^{c} \mathrm{p}<.001$.

${ }^{d}$ Excludes comments with commenter betweenness value of 0 .

TABLE 3 | Correlation matrix of model variables.

\begin{tabular}{|c|c|c|c|c|c|c|c|c|}
\hline & $\begin{array}{l}\text { Message } \\
\text { sentiment }\end{array}$ & $\begin{array}{l}\text { Commenter } \\
\text { degree }\end{array}$ & $\begin{array}{l}\text { Commenter } \\
\text { betweenness }\end{array}$ & $\begin{array}{c}\text { Commenter } \\
\text { tenure }\end{array}$ & $\begin{array}{l}\text { Author } \\
\text { degree }\end{array}$ & $\begin{array}{l}\text { Author } \\
\text { tenure }\end{array}$ & $\begin{array}{c}\text { Initial } \\
\text { post } \\
\text { sentiment }\end{array}$ & $\begin{array}{c}\text { Commenter } \\
\text { sentiment } \\
\text { profile }\end{array}$ \\
\hline Message Sentiment & 1.00 & -0.04 & -0.05 & -0.10 & 0.03 & -0.01 & 0.06 & 0.22 \\
\hline Commenter Degree & -0.04 & 1.00 & -0.61 & -0.43 & 0.04 & 0.34 & -0.08 & -0.03 \\
\hline Commenter Betweenness & -0.05 & -0.61 & 1.00 & -0.01 & 0.01 & 0.05 & -0.25 & -0.36 \\
\hline Commenter Tenure & -0.10 & -0.43 & -0.01 & 1.00 & 0.11 & -0.77 & 0.12 & 0.16 \\
\hline Author Degree & 0.03 & 0.04 & 0.01 & 0.11 & 1.00 & -0.13 & -0.22 & -0.12 \\
\hline Author Tenure & -0.01 & 0.34 & 0.05 & -0.77 & -0.13 & 1.00 & -0.14 & -0.14 \\
\hline Initial Post Sentiment & 0.06 & -0.08 & -0.25 & 0.12 & -0.22 & -0.14 & 1.00 & 0.28 \\
\hline $\begin{array}{l}\text { Commenter Sentiment } \\
\text { Profile }\end{array}$ & 0.22 & -0.03 & -0.36 & 0.16 & -0.12 & -0.14 & 0.28 & 1.00 \\
\hline
\end{tabular}

negatively associated with peer approval of a remedial narrative, particularly when connectedness is measured by tenure. The more temporally established the member is in the community, the more likely they are to engage in exclusionary boundary work. Inversely, the more recently the member joined the community, the more likely they are to react positively to failure narratives.

This implies that peripheral community members are more likely than core members to re-affirm a remedial member's membership. As Figure 3 demonstrates, most responses to failure narratives in this community are positive. Qualitative content analysis of comments and interviews with entrepreneurs suggest that boundary work in such virtual peer communities is not predominantly negative policing, but positive bonding (see examples of positive comments in Table 4).

The large scale of Reddit provides insight into the sociocentric context of conversations amongst peer entrepreneurs. To learn more about the value and meaning of dyadic peer reactions to failure narratives, the author interviewed five failure narrative authors and one commenter. This selection was limited by the ability to contact individuals in a semi-anonymous setting. All interviews were conducted over the teleconferencing tool Skype. Interviewees signed a statement of consent and the interview protocol was approved by the university institutional review board.

From the qualitative content analysis and interviews, the author finds that peers indeed play a critical role in making sense of and recovering from failure. This is particularly so among peers that can empathize with the failure experience. Moreover, these interactions expand beyond the virtual to offline relationships. These interactions decay over time following the failure narrative, yet imprint both the narrator and the peer's subsequent entrepreneurial 


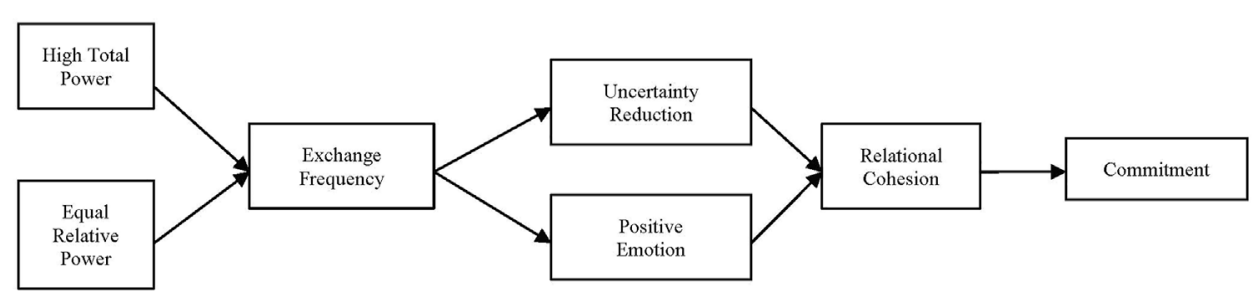

FIGURE 6 | Scatterplot of Commenter Tenure (Logged) and Sentiment of Response to Failure Narrative, with Fitted Linear Predicted Values in red.

TABLE 4 | Examples of positive comments from/r/entrepreneur subreddit.

"Great write up! thanks for this - as I am in the early stages of launching my first campaign. Did you have an email list before launch? How was your experience? Do you recommend it?"

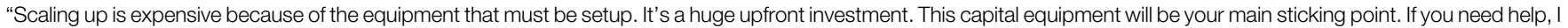
would be interested. "

"Thanks for sharing this. You have to keep going brother."

"Brilliant post. Having recently closed my own company after more than 10 years, I agree with the lessons here, especially on blaming process."

"I'm 25 as well and testing stuff) Keep going, you will overcome the struggle. I could help you with your website."

Note: Paraphrased to protect subject privacy.

decisionmaking. While negative commentary in our virtual community may be generally perceived as "trolling" or otherwise inconsequential, positive commentary has a clear impact on failure narrative authors. The findings from interviews with fail post authors and commenters explain how failure narrators are able to circumvent negative gatekeepers and access community social capital to recover from failure.

\section{Peers Empathize With Failure}

Through the public failure narrative, authors connect with anonymous outreachers in addition to acquaintances. One author stated:

"I got a lot of response from the postmortem. People from all over the world. People working on similar things and wanting help. And other post mortem victims, survivors. That was very cool. Talking to other people who went through the same thing."

Another author stated that:

"There was a lot of online and sidebar discussion. It was surprising to me honestly. Founders reaching out in the backchannel who had similar stories. It was good to hear. Maybe their startup wasn't as well known, but it was similar emotions, similar pain. Shared catharsis. I got emails, phone calls from people asking, can we talk it over."

Another author exclaimed: "it was a full spectrum-folks you'd never heard of, and folks you had a casual or deep relationship with. Peers. Lots of folk." One failure narrative author described how he began reaching out to other failed entrepreneurs after his failure:

"I will email people who I see go out of business and write them a note even if I don't know them. It happened a couple months ago, just say, I really liked what you were doing, just offering my support and if you need to talk, here's my number, call me. I usually get an email back. And I understand-most people don't want to talk about it, right at the beginning. But you feel like you're on this island, there's not a lot of people you can talk to. You can't really talk-I mean I guess you could, but, it's not something I feel comfortable talking to my family about because they're not in business, they're in healthcare and stuff like that. Same with my wife-at the time my girlfriend. ... I remember the phone call from TechCrunch, when they were like, oh, we have to write about this closing. I was like, shit. I wished we could just go quietly, and we would be done.... But with that it feels like such a punch in the face. So it just sucks. Those are the people I usually reach out to, because I've been in those shoes and it just sucks."

A peer described how he followed up with a failure narrative author offline:

"When (X) shared the postmortem, I had a beer with him and talked with him about winding down the company. His realization was that "we needed dollars or we were going to die." It was an "aha" moment-we 
were facing the same problem (in the consulting inititative). It led me to be more curious about challenges in other industries-maybe there is a painkiller (rather than vitamin business model) out there."

Not all entrepreneurs wanted this attention:

"(After the failure, I received) a lot of emails and phone calls and texts and 'keep your head up' kind of thing. Which was really nice. In hindsight it's nice, but when it happens, it's like oh shit, they saw too. <chuckles> And they know, they were watching. I got a couple really great emails from some people that I knew, that were in the extended network, and then some people that I didn't know who just used the service and just said, hey, I used this and I loved it and it sucks that it's going away. And that was kind of cool."

Relationships develop between outreachers and authors:

"you build relationships out of postmortems. A few of them I've certainly kept up with over the years, followed their pursuits, their startups. There's a certain camaraderie that comes out of that. Shared battle scars. Whether it's a couple thousand or twenty million [dollars lost], pain is still the same."

\section{Peer Affirmation Results in Social Capital and Persistence}

These interactions impact entrepreneurs' careers, both of failure narrative authors and commenters. When asked how his own postmortem impacted his career, a peer commenter responded: "A lot. Besides friends saying 'I'm very sorry. By the way, would you like to come work with us?', people I've never met in my life, from different corners of the world, said 'hey, I read that, I found it interesting, do you want to chat." As one peer commenter described, these outreach gestures, which occurred over email, LinkedIn, Twitter, and skype calls, happened "more around the time of the postmortem. They changed my insights about generic stuff. It was mostly spontaneous." Another peer describes how the interactions ebbed over time, but had an impact on his career:

"I haven't chatted with him much since. I opened an office in (another region)-I go back and forth. He's good people. We are up for a loan in (the state). I reached out to him to get guidance on it. He's been really helpful with investor relations. His tactics helped us close a $\$ 500 \mathrm{~K}$ round, helped us create a great pitch, how to get money from the state."

From the content of failure narrative discussion threads and interviews with narrative authors and commenters, it is clear that boundary work in this context is about support rather than exclusion. Entrepreneurs are often already stigmatized in broader society and face criticism for the risks they undertake. To secure support, entrepreneurs must be skilled optimists. They have learned to ignore criticism as noise.

Failure is generally stigmatized. Yet, through public peerto-peer failure narratives, failed entrepreneurs are able to connect in an emergent peer support network. The interviews described above demonstrate the value of these peer support ties. Based on findings in other contexts, such as cancer patient and alcoholic peer support networks (c.f. Fowler and Christakis 2008; Zhang and Centola 2019), it is likely that peer support ties increase the retention and performance of failed entrepreneurs. Indeed, many outreachers in the dataset are actively involved in supporting entrepreneurship as event or community organizers.

\section{DISCUSSION}

The goal of this study is to understand how remedial boundary work operates in virtual communities of practice, where boundaries are ambiguous and resources intangible. In closed exchange networks, central actors are generally more likely to engage in gatekeeping. The relationship between network position and gatekeeping in open exchange networks, however, has not been as well understood. Thus, the goal of this study is to address the question of how network position, namely centrality, influences a community member's gatekeeping behavior in an open exchange network. To address this question, this study analyzed the relationship between peer network position and the sentiment of their response to failure narratives, assuming that remedial narratives provoke peer gatekeeping. The study finds that central peers, particularly more established members of the community with longer tenure, do indeed engage in more exclusionary boundary work. However, more importantly, the study shows that peripheral peers engage in more inclusive boundary work that is more impactful to remedial members. Through positive peer affirmation, remedial members are able to regain access to community-specific social capital and redress their reputation following failure. These findings contribute directly to the theorization of social exchange commitment; remedial boundary work, social capital, and knowledge production in virtual communities of practice; and the methodological study of remedial and discursive boundary work in porous or semi-anonymous communities.

\section{Implications for Social Exchange Commitment}

Remedial actions can result in exclusive boundary work that isolates the transgressor from the "flock." However, remedial action can also result in cohesion, as when a sub-community bonds over the shared remedial experience ("shared battle scars"). This study finds that both inclusive and exclusive boundary work occurs, and is associated with peer tenure in the community network. Inclusive boundary work is particularly prevalent (mean $=0.1025)$. By investigating the content of the discussion ties in this network, the author observes many instances of outreach for 
empathy, relationship-building, and knowledge exchange (see Table 4).

Membership affirmation is a form of exchange commitment. Lawler and Yoon (1996) theorized that positive emotions generated from interactions can produce commitment to an exchange relationship. Relational cohesion theory identifies emotion as the mechanism for exchange commitment under suboptimal conditions, such as when an exchange partner fails to meet prior expectations (c.f. Uzzi 1997). Through positive emotion during prior exchange, partners come to associate the exchange relationship with positive affect (Lawler and Yoon 1996; Lawler and Yoon 1998; Thye et al., 2002; Lawler 2010). Through this "relational cohesion" process, the exchange relationship becomes an object of commitment.

The main drivers of relational cohesion, according to this theory, are power, exchange frequency, and positive emotion (see Figure 6 below). Power and exchange frequency can manifest in network centrality. Critically, however, relational cohesion is distinct from structural cohesion. In relational cohesion, the value of the relationship is not based on structural dependencies, as in brokerage-based gatekeeping. Instead, the relationship is valued by its emotional content. The key driver of relational cohesion in this theory is emotion, or "relatively shortlived positive or negative feeling states" (Thye, Yoon, and Lawler 2002:15). In particular, Thye, Yoon, and Lawler assert that positive emotion, namely "pleasure/satisfaction and interest/ excitement" will cause exchange partners to "partially attribute their (positive) emotions to their relation." In turn, "positive emotions induce a shift in cognitive awareness, such that actors come to see their relation as being more important, stable, and valued over time." The authors theorize that exchange frequency should induce such positive emotion, given that exchange frequency reduces uncertainty (Cook and Emerson 1984; Kollock 1994, 1999).

Failure may not induce positive emotions. It does, however, produce empathy. Like soldiers swapping war stories, these findings show that entrepreneurs bond and build camaraderie over failure narratives. As one peer responded to a failure narrative: "Thanks for sharing this, you have to keep grinding brother." Emotion does not need to be positive, and can indeed be negative, to stabilize a bond. The key is that the emotion is shared and produces empathy.

Given these findings, relational cohesion extends beyond positive emotion to include shared emotion, or empathy. Through failure narratives, and the empathy it provokes, remedial narrators are able to develop relational cohesion with empathizing members of the community and recover lost reputation following failure. This extension of relational cohesion explains why failure narrators are able to circumvent negative gatekeepers and re-establish themselves in the community. Relational cohesion theory also explains why peripheral community members are more supportive of failure narratives than centralized members. In 2000, Lawler, Thye, and Yoon extended relational cohesion theory to "productive exchange" contexts. In contrast to the dyadic nature of negotiated, reciprocal, and generalized exchanges, resources and benefits in productive exchanges flow between the individual and the group (Emerson 1976; Molm and Cook 1995; Thye et al., 2002). In their theorization of productive exchange, Lawler et al. (2000) introduced uncertainty reduction as a mechanism for commitment "distinct, yet complementary" to emotion (see Figure 6 below). The authors theorized that uncertainty reduction, through frequent exchange, made an exchange "more familiar and predictable."

It is this uncertainty reduction mechanism that, the author theorizes, explains the relationship between peer centrality and peer affirmation. Peripheral peers should exhibit higher uncertainty than centralized peers. Peripheral peers are newer to the community, have less information, and are otherwise isolated from other practitioners. In contrast, central peers enjoy the benefit of not only their own knowledge but that of the other most connected peers in the community network, as a function of their central network position. Thus, peripheral peers have a higher state of uncertainty. Moreover, the failure narrative primes the relationship for uncertainty reduction. Failure is the manifestation of high uncertainty. Failure narratives are an artifact of the sensemaking process, an attempt to reduce uncertainty through collective and cognitive information seeking as well as to remediate the violation of practitioner norms through the sharing of the narrative (Weick et al., 2005).

Rather than decreasing exchange commitment, however, the author argues that this uncertainty 1) incentivizes peripheral peers to engage with remedial narrators and 2) amplifies their empathy and tolerance of failure and other remedial behavior. Peripheral peers are more incentivized to reduce their higher states of uncertainty than central peers, who enjoy lower perceived uncertainty. Peripheral peers are therefore more inclusive in seeking social relationships to reduce uncertainty (Cook and Emerson 1984; Kollock 1994; Karen and Eric, 2013).

Thus, peripheral peers, with higher uncertainty, bond with remedial narrators over a shared emotion exhibited in the failure narrative. This bonding circumvents the gatekeeper, effectively unlocking the community's network, giving the remedial member renewed access to the community's social capital, via the peripheral peer, and ultimately reviving the remedial member's reputation following failure. This relationship is modeled in Figure 7 below, modifying Figure 1 to incorporate and extend relational cohesion theory to include empathy (not just positive emotion) and peripheral peer uncertainty.

These findings make important contributions to social exchange commitment theory. Social exchange theory can be used to predict exchange relations in virtual communities given network structure and an assumed degree of rational action (c.f. Faraj and Johnson 2011). However, exchange relations persist despite more logical alternatives. When an exchange partner admits failure, for example, their reputation and desirability as an exchange partner should suffer. Relational cohesion theory (Thye et al., 2002) explains why actors commit to exchange relations even in the face of better options. This study extends relational cohesion theory to the boundary work 


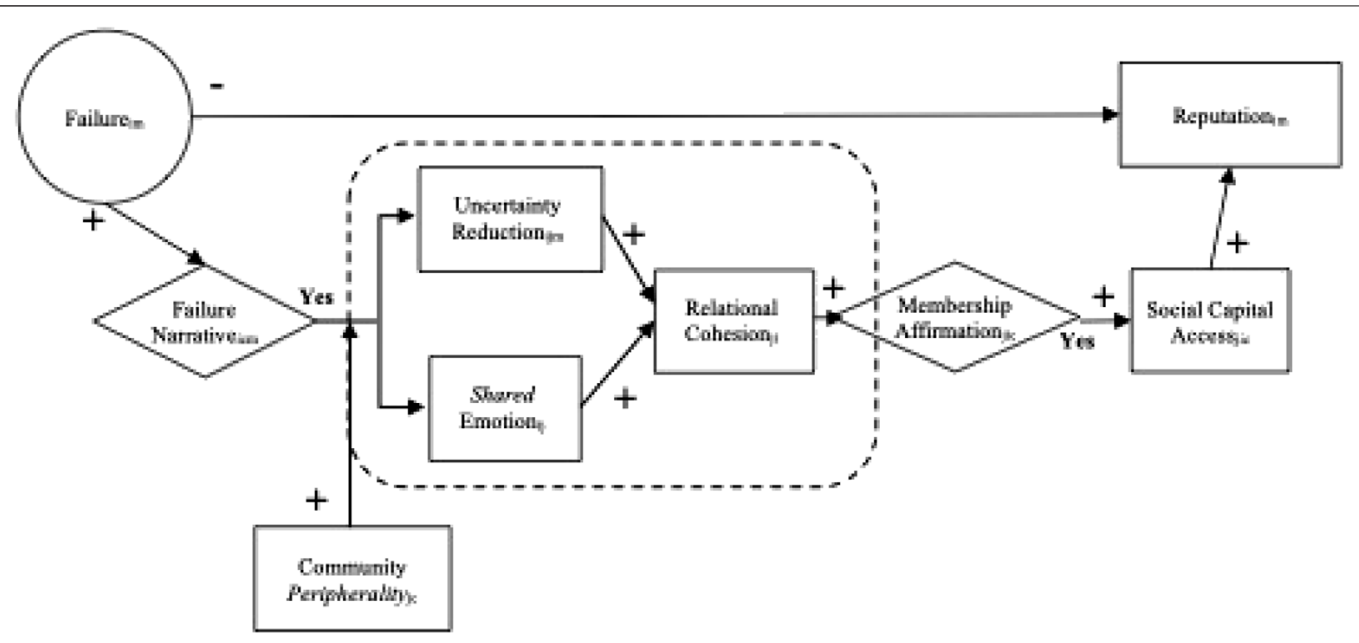

FIGURE 7 | Relational cohesion theory in productive exchange context (adapted from Thye, Yoon, and Lawler 2002).

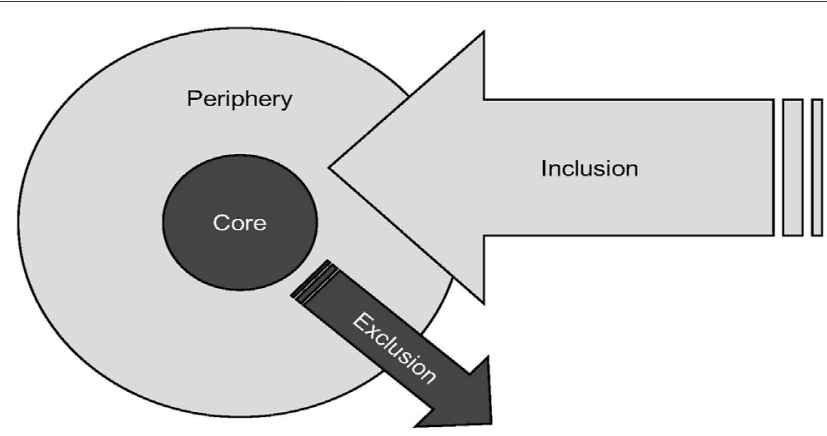

FIGURE 8|Peripheralized Enabling of peer Affirmation of Community Membership as inclusionary Remedial Boundary Work. The less central (and more peripheral) the peer $\mathrm{j}$ in community c, the more likely they are to embrace a failure narrative and re-affirm the remedial member i's membership in community c. This is because the peripheral member j 1) experiences higher uncertainty than more central members and thus seeks to reduce uncertainty through the failure narrative as a part of the collective sense making process; and 2) bonds over the shared emotion expressed in the failure narrative. This produces relational cohesion, through which the peers mutually affirm each other's membership in community c.

context, in which membership and community social capital are the objects of exchange.

Relational cohesion theory identifies emotion as the mechanism that bonds actors into a united exchange relationship that is valuable beyond the transaction and against otherwise logically preferable alternatives. Emotion, however, is complex. As demonstrated by hazing and other painful initiation rites, it is not simply positive emotions that generate bonding, but also shared negative emotions (Aronson and Mills 1959). This study expands emotions as a mechanism for relational cohesion to include negative but empathetic emotions.

Social exchange theory recognizes that one benefit of relational cohesion is the reduction of exchange uncertainty. Thye et al. (2002) model uncertainty reduction as a complementary mechanism explaining commitment to underperforming relationships. Peripheral community members are also associated with higher uncertainty. This study leverages the association between network peripherality and exchange uncertainty to theorize the positive relationship between peripherality and inclusive boundary work.

\section{Implications for Boundary Work in Virtual Communities}

Local centrality does not appear to matter as much as global measures of connectedness and tenure in virtual peer community boundary work. Rather than tabloids on who is attending whose party, the virtual public forum is more like walled classrooms with open doors on a large university campus: anyone can enter, but your chance of being aware of every discussion is minimal. The virtual public forum is thus an open rather than closed network. Nan Lin (1999) summarized the distinct views of networks as social capital, including the benefits of closed or open networks (Bourdieu, 1986; Coleman 1990; Putnam 1993, 1995). In this view, closed networks generate a premium of 
"collective capital" via closure, or exclusivity. Lin asserts that closed networks are beneficial for "preserving or maintaining resources," but are counterproductive for "searching and obtaining resources" (c.f. Granovetter 1974). From the initial description of our online entrepreneurial community (see above), posted by the community founder, it is clear that this community seeks the latter.

Entrepreneurs turn to their peers to make sense of and recover from failure, but these interactions are steeped in identity work. The virtual community of entrepreneurs is a resource for social capital, information, and other goods, but it is also an expressive forum for definition and development of the entrepreneurial identity. Wenger (1998) notes that communities of practice foster identity as well as learning. Communities of peers are simultaneously learning as a collective, fostering a shared identity, and competing over resources that include social capital. This analysis of the relationship between community centrality and boundary work identifies this tension between the peer community as both an instrumental and an expressive network, but finds that, as an open rather than closed network, community boundaries are more inclusively fostered rather than exclusively policed.

Boundary work is a process of separating in-group from outgroup. Boundary work is a social force in two opposing directions: pushing out and pulling in. Prior scholarship has focused predominantly on only one of these forces: exclusion (Lamont and Molnar 2002). Hypothesis 1 describes the exclusion force of boundary work. This hypothesis is that the higher quality, higher status, embedded, even institutionalized, core generally push outsiders away from the group. These findings demonstrate the presence and the importance of the inclusion force. The findings show that the core does exclude. However, the author also finds that the periphery includes, and that this inclusion may be more influential to communal membership, social capital, and specifically reputation. This dynamic is visualized in Figure 8.

In this open network, where the object of exchange is information and social capital, and where members do not compete over resources, exchange follows reciprocity rather than preferential attachment (Faraj and Johnson 2011). While high-status core members with a stronger sense of certainty push out remedial members, lower-status, marginalized peripheral members with higher uncertainty pull remedial members back into the fold. While the core can be powerful gatekeepers, the periphery can be more pivotal in (inclusive) boundary work, at least in virtual communities of practice. In the r/Entrepreneur virtual community, the pull is more influential than the push. Because the network is open and semi-anonymous, negative reputations can be more easily replaced with new identities (Cook, 2009). However, building a positive reputation is more challenging in this context. Inclusive boundary work, therefore, is not only a bridge into the community, but more powerful.

This study directly contributes to the debated role of structural position in knowledge communities, namely whether network centrality is positively or negatively associated with knowledge creation and the mechanisms through which this knowledge creation occurs. Safadi et al. (2020), for example, describing the "core-periphery debate in knowledge fields," similarly find that marginal members contribute knowledge to the community, but explain this duality by distinguishing structural position in the virtual community from epistemic position. A related subset of this conversation is the tension between peripheral novelty and influence, often conceptualized as "boundary spanning" (c.f. Rosenkopf and Nerkar 2001). Vedres and Stark (2010), for example, theorize "structural folds" as the balanced position of enough marginality to access new ideas and enough embeddedness to enact those ideas. It is important to note that boundary spanning is distinct from community marginality and boundary work. Boundary spanning generally assumes that the boundary is set and even static, analyzing those who bridge communities rather than the formation and evolution of boundaries (Langley et al., 2019). In contrast, boundary work focuses on the ongoing negotiation of boundaries. The relationship between boundary work and knowledge management, and the capability of gatekeeping to control and inhibit knowledge, has received too little empirical analysis. This analysis is especially critical for communities of practice, where the practice and the legitimacy of practitioners are defined by community knowledge.

These findings show that 1) discursive boundary work occurs in virtual communities, 2) inclusive boundary work is more impactful (and thus circumvents exclusive gatekeeping), and 3) peripheral community members respond more positively to remedial narratives. Through empathy and collective sensemaking of the failure, peripheral community members bond with remedial members. This relational cohesion facilitates access to valuable resources like financial, labor, informational, or emotional support, which assist the remedial member in recovering from failure. This means that peripheral members are the key to a remedial member's recovery from failure.

This study also contributes methodologically to the study of remedial and discursive boundary work in porous or semianonymous communities. Boundary work is most commonly applied to newcomers who aspire to gain access to a community. But it is perhaps even more salient for remedial members who have demonstrated poor quality and have earned a reputational penalty that calls their community membership into question. In the case of aspirational membership, boundary workers must assess the quality of aspirational members under conditions of high uncertainty. Because remedial members have a history in the community and are confessed remedials, boundary workers have a more certain perception of quality of these members and can more certainly determine their belonging to the community. Thus, the boundary work of remedial members deserves theoretical attention.

Remedial boundary work is important for two reasons. First, remedial boundary work is a clearer signal of membership worth in a porous, semi-anonymous community in which boundary workers face a high degree of uncertainty about aspirational members' worth to the community. Second, remedial boundary work is theoretically important because, in a community context reliant on discursive interaction such as an online discussion forum, both the remedial narrative and the boundary work it provokes are observable in documented 
discourse, namely the "remedial narrative." In virtual communities where semi-anonymous members rely on discussion boards, tweets, threads, and other text formats, boundary work is discursive (c.f. Honeycutt 2005; Shaw 2012). Rhetoric is a form of boundary work in a porous community where traditional status symbols are unavailable (e.g., online anonymity) or where legal barriers to entry do not exist (e.g., entrepreneurship).

The foundation of boundary work theorization is based in discourse and knowledge production (c.f. Gieryn 1983). As discursive boundary work is increasingly documented in digital settings, natural language processing and computational network analysis enable new empirical analyses and theorization of boundary work. This study takes advantage of the network and text data generated by virtual communities on the Reddit platform, and the statistical analyses this data makes possible. Using the network and text analysis methods introduced here, and the nuanced measures that these methods enable, scholars of boundary work can refine their understanding of the mechanisms behind boundary work in complex contexts, such as porous or semi-anonymous communities.

\section{CONCLUSION AND FUTURE RESEARCH}

This study tested a network argument for discursive boundary work in a virtual peer community. The author evaluated whether something about the network-not just dyads, but the aggregation of ties and shifting position that entails, might cause community members to police against failed members. The author proposed that exclusion and outreach, forms of community boundary work, may depend on the network structure, namely centrality, of the boundary worker. This is suggested by theories of network exchange and inter-group dynamics, and reflected in observations from failure narratives published online. These dynamics could have a critical impact on community vitality, including creativity and network learning, if excluders gatekeep and outreachers broker access between membership claimers and the community core. The study tests this theory using network and text data from discussions posted to the/r/Entrepreneur virtual community of practice. The author finds that connectedness and tenure do influence message sentiment. However, through interviews with entrepreneurs, the author learns that messages of inclusion are important to the entrepreneur's sense of belonging and commitment to the occupation. Thus, while the boundary worker's position in the sociocentric network may negatively influence their boundary work, the boundary work itself may positively influence the community network by retaining members and strengthening their ties to the virtual community. This is a clear example of why egocentric network analysis (Perry et al., 2018) cannot be devalued, and may be even more useful for uncovering behavior unseen at the sociocentric level of analysis.

Future research can address two important limitations in this study. Sentiment is incredibly complex (c.f. Scherer 1984). Accurately analyzing sentiment requires context about the narrator and the audience, such as their relationship, goals, preferences, history, norms, and restrictions. This study uses a simplified measure of boundary work: QDAP sentiment score.
Sentiment is much more nuanced than this single measure affords. Future research should test a variety of measures of boundary work, including the separation of negative and positive responses into distinct variables. It is possible, for example, that a comment includes both negative and positive terms. Moreover, sentiment varies based on who is exhibiting or observing its expression. Future studies may capture boundary work more accurately by measuring sentiment directed at specific targets, rather than overall sentiment of the document.

Finally, these findings may be specific to the/r/Entrepreneur subreddit context. This empirical context restricts the generalizability of these findings in several ways. Entrepreneurial failure may be distinct from other types of failure. Entrepreneurial failure narratives might provoke distinct dynamics from other types of remedial narratives. This field site is an open network with unrestricted resources. Dynamics observed here may be different for closed networks in which members compete over resources. Finally, social capital and reputation may entail distinct dynamics for entrepreneurs in a virtual community in contrast to non-entrepreneurs or local entrepreneurs. In order to generalize these findings, the hypothesis should be tested in other virtual peer communities.

Connectedness influences boundary work. Exclusion and outreach are dyadic interactions influenced by ego network structures that have community-level implications. The vitality of the community relies on learning from remedial experiences like failure. Such learning hinges on community boundary work.

\section{DATA AVAILABILITY STATEMENT}

The raw data supporting the conclusion of this article will be made available by the authors, without undue reservation.

\section{ETHICS STATEMENT}

The studies involving human participants were reviewed and approved by the Stanford University IRB Protocol \# 36569. The patients/participants provided their written informed consent to participate in this study.

\section{AUTHOR CONTRIBUTIONS}

The author confirms being the sole contributor of this work and has approved it for publication.

\section{FUNDING}

The article processing fees to publish this article are paid from the University of California, Santa Barbara Early Career Faculty Acceleration Program, an initiative to help untenured faculty advance scholarly activities in the wake of the pandemic, by providing financial assistance to accelerate and enhance research, creative activities, and professional development. 


\section{REFERENCES}

Abbott, A. (1983). Professional Ethics. Am. J. Sociol. 88 (5), 855-885. doi:10.1086/ 227762

Abbott, A. (1995). Things of Boundaries. Soc. Res. 62 (4), 857-882.

Adler, P. S., Kwon, S.-W., and Heckscher, C. (2008). Perspective-Professional Work: The Emergence of Collaborative Community. Organ. Sci. 19 (2), 359-376. doi:10.1287/orsc.1070.0293

Alan Fine, G. (2019). Moral Cultures, Reputation Work, and the Politics of Scandal. Annu. Rev. Sociol. 45, 247-264. doi:10.1146/annurev-soc073018-022649

Albert, R., and Barabási, A.-L. (2002). Statistical Mechanics of Complex Networks. Rev. Mod. Phys. 74 (1), 47-97. doi:10.1103/revmodphys.74.47

Arguello, J., Butler, B. S., Joyce, L., Kraut, R., Ling, K. S., and Rosé, C. (2006). “Talk to Me: Foundations for Successful Individual-Group Interactions in Online Communities," in Proceedings of the SIGCHI Conference on Human Factors in Computing Systems (CHI '06) (New York, NY: Association for Computing Machinery), 959-968. doi:10.1145/1124772.1124916

Aronson, E., and Mills, J. (1959). The Effect of Severity of Initiation on Liking for a Group. J. Abnormal Soc. Psychol. 59, 177-181. doi:10.1037/h0047195

Autio, E., Dahlander, L., and Frederiksen, L. (2013). Information Exposure, Opportunity Evaluation, and Entrepreneurial Action: An Investigation of an Online User Community. Amj 56 (5), 1348-1371. doi:10.5465/ amj.2010.0328

Becker, H. S. O. (2008). Simon and Schuster. Available at: https://www. simonandschuster.co.in/.

Berger, J., Cohen, B. P., and Zelditch, M., Jr. (1972). Status Characteristics and Social Interaction. Am. Sociological Rev. 37, 241-255. doi:10.2307/2093465

Bonacich, P. (1987). Power and Centrality: A Family of Measures. Am. J. Sociol. 92 (5), 1170-1182. doi:10.1086/228631

Borgatti, S. P., and Halgin, D. S. (2014). "Analyzing Affiliation Networks," in The SAGE Handbook of Social Network Analysis. Editors J. Scott and P. J. Carrington (Springer).

Bourdieu, P. (1984). Translated by Richard Nice. Distinction: A Social Critique of the Judgement of Taste. Cambridge, MA: Harvard University Press.

Bourdieu, P. (1986). "The Forms of Capital," in Handbook of Theory and Research for the Sociology of Education. Editor J. Richardson (Westport, CT: Greenwood), 241-258.

Broido, A. D., and Clauset, A. (2018). Scale-free Networks Are Rare. Available at: https://arxiv.org/abs/1801.03400v1.

Burt, R. S. (1992). Structural Holes. Harvard University Press.

Buyukozturk, B., Gaulden, S., and Dowd-Arrow, B. (2018). Contestation on Reddit, Gamergate, and Movement Barriers. Soc. Mov. Stud. 17 (5), 592-609. doi:10.1080/14742837.2018.1483227

Cardon, M. S., Stevens, C. E., and Potter, D. R. (2011). Misfortunes or Mistakes? J. Business Venturing 26 (1), 79-92. doi:10.1016/j.jbusvent.2009.06.004

Cartwright, D., and Harary, F. (1956). Structural Balance: a Generalization of Heider's Theory. Psychol. Rev. 63 (5), 277-293. doi:10.1037/h0046049

Choi, B. R., Alexander, K., Kraut, R. E., and Levine, J. M. (2010). "Socialization Tactics in Wikipedia and Their Effects CSCW'10," in Proceedings of the ACM Conference on Computer-Supported Cooperative Work (ACM), 107-116.

Clauset, A., Newman, M. E., and Moore, C. (2004). Finding Community Structure in Very Large Networks. Phys. Rev. E Stat. Nonlin Soft Matter Phys. 70 (6), 066111. doi:10.1103/PhysRevE.70.066111

Coleman, J. S. (1990). Foundations of Social Theory. Harvard University Press.

Comeau-Vallée, M., and Langley, A. (2020). The Interplay of Inter-and Intraprofessional Boundary Work in Multidisciplinary Teams. Organ. Stud. 41 (12), 1649-1672.

Constant, D., Sproull, L., and Kiesler, S. (1996). The Kindness of Strangers: The Usefulness of Electronic Weak Ties for Technical Advice. Organ. Sci. 7 (2), 119-135. doi:10.1287/orsc.7.2.119

Cook, K. S. (2009). Department of Industrial Engineering and Innovation Sciences," in Chris Snijders (Springer). Editors V. Buskens and C. Cheshire.

Cook, K. S., and Emerson, R. M. (1984). Exchange Networks and the Analysis of Complex Organizations. Res. Sociol. Organizations 3 (4), 1-30.
Cook, K. S., Emerson, R. M., Gillmore, M. R., and Yamagishi, T. (1983). The Distribution of Power in Exchange Networks: Theory and Experimental Results. Am. J. Sociol. 89 (2), 275-305. doi:10.1086/227866

Cook, K. S., and Emerson, R. M. (1978). Power, Equity and Commitment in Exchange Networks. Am. Sociological Rev. 43, 721-739. doi:10.2307/2094546

Cook, K. S. (1977). Exchange and Power in Networks of Interorganizational Relations. Sociological Q. $18 \quad$ (1), 62-82. doi:10.1111/j.15338525.1977.tb02162.x

Cook, K. S., and Santana, J. J. (2020). "Trust: Perspectives in Sociology," in The Routledge Handbook of Trust and Philosophy (Springer), 15. doi:10.4324/ 9781315542294-15

Cornwell, B. (2005). A Complement-Derived Centrality index for Disconnected Graphs. Connections 26 (2), 70-81.

Corra, M., and Willer, D. (2002). The Gatekeeper. Sociological Theor. 20 (2), 180-207. doi:10.1111/1467-9558.00158

Davis, A., Gardner, B., and Gardner, R. (1941). Deep South. University of Chicago Press.

Dowling, D. O., Goetz, C., and Lathrop, D. (2020). One Year of \#GamerGate: The Shared Twitter Link as Emblem of Masculinist Gamer Identity. Games Cult. 15 (8), 982-1003. doi:10.1177/1555412019864857

Emerson, R. M. (1976). Social Exchange Theory. Annu. Rev. Sociol. 2 (1), 335-362. doi:10.1146/annurev.so.02.080176.002003

Faraj, S., Jarvenpaa, S. L., and Majchrzak, A. (2011). Knowledge Collaboration in Online Communities. Organ. Sci. 22 (5), 1224-1239. doi:10.1287/ orsc. 1100.0614

Faraj, S., and Johnson, S. L. (2011). Network Exchange Patterns in Online Communities. Organ. Sci. 22 (6), 1464-1480. doi:10.1287/orsc.1100.0600

Faraj, S., von Krogh, G., Monteiro, E., and Lakhani, K. R. (2016). Special Section Introduction-Online Community as Space for Knowledge Flows. Inf. Syst. Res. 27 (4), 668-684. doi:10.1287/isre.2016.0682

Fine, G. A., and Kleinman, S. (1979). Rethinking Subculture: An Interactionist Analysis. Am. J. Sociol. 85 (1), 1-20. doi:10.1086/226971

Fowler, J. H., and Christakis, N. A. (2008). Dynamic Spread of Happiness in a Large Social Network: Longitudinal Analysis over 20 Years in the Framingham Heart Study. Bmj 337, a2338. doi:10.1136/bmj.a2338

Freeman, L. C. (1979). Centrality in Social Networks Conceptual Clarification. Social Networks 1 (3), 215-239.

Freidson, E. (1988). Profession of Medicine: A Study of the Sociology of Applied Knowledge. University of Chicago Press.

Gieryn, T. F. (1983). Boundary-work and the Demarcation of Science from Nonscience: Strains and Interests in Professional Ideologies of Scientists. Am. Sociological Rev. 48 (6), 781-795. doi:10.2307/2095325

Glaser, B. G. (2001). The Grounded Theory Perspective: Conceptualization Contrasted with Description. Mill Valley, CA: Sociology Press.

Goffman, E. (1971). Relations in Public: Microstudies of the Public Order. Basic Books.

Golder, S. A., and Macy, M. W. (2014). Digital Footprints: Opportunities and Challenges for Online Social Research. Annu. Rev. Sociol. 40, 129-152. doi:10.1146/annurev-soc-071913-043145

Gould, R. V., and Fernandez, R. M. (1989). Structures of Mediation: A Formal Approach to Brokerage in Transaction Networks. Sociological Methodol. 19, 89-126. doi:10.2307/270949

Granovetter, M. (1985). Economic Action and Social Structure: The Problem of Embeddedness. Am. J. Sociol. 91 (3), 481-510. doi:10.1086/228311

Granovetter, M. (1974). Getting a Job: A Study of Contacts and Careers. University of Chicago Press.

Granovetter, M. (2017). Society and Economy. Harvard University Press.

Hamann and Beljean (2019). Career Gatekeeping in Cultural fields. Am. J. Cult. Sociol. 9, 1-27. doi:10.1057/s41290-019-00078-7

Heider, F. (1946). Attitudes and Cognitive Organization. J. Psychol. 21 (1), 107-112. doi:10.1080/00223980.1946.9917275

Honeycutt, C. (2005). Hazing as a Process of Boundary Maintenance in an Online Community. J. Computer-Mediated Commun. 10 (2), 1021

Hwang, E. H., Singh, P. V., and Argote, L. (2015). Knowledge Sharing in Online Communities: Learning to Cross Geographic and Hierarchical Boundaries. Organ. Sci. 26 (6), 1593-1611. doi:10.1287/orsc.2015.1009

Jenkins, R. (1996). Social Identity. London: Routledge. 
Johnson, S. L., Safadi, H., and Faraj, S. (2015). The Emergence of Online Community Leadership. Inform. Syst. Res 26 (July), 35-68. doi:10.1287/isre.2014.0562

Jones, S. (1998). Cybersociety 2 .0: Revisiting Computer-Mediated Communication and Community. Newbury Park, CA: Sage Publications.

Jones, S. (1997). Virtual Culture: Identity and Communication in Cybersociety. Newbury Park, CA: Sage Publications.

Kane, G. C., and Ransbotham, S. (2016). Content as Community Regulator: The Recursive Relationship between Consumption and Contribution in Open Collaboration Communities. Organ. Sci. 27 (5), 1258-1274. doi:10.1287/ orsc.2016.1075

Karen, S. C., and Eric, R. (2013). "Social Exchange Theory," in Handbook of Social Psychology. Handbooks of Sociology and Social Research. Editors D. John and W. Amanda (Springer).

Kibler, E., Mandl, C., Kautonen, T., and Berger, E. S. C. (2017). Attributes of Legitimate Venture Failure Impressions. J. Business Venturing 32 (2), 145-161. doi:10.1016/j.jbusvent.2017.01.003

Kogut, B., and Zander, U. (1996). What Firms Do? Coordination, Identity, and Learning. Organ. Sci. 7 (5), 502-518. doi:10.1287/orsc.7.5.502

Kollock, P. (1999). "The Economies of Online Cooperation: Gifts and Public Goods in Cyberspace," in Communities in Cyberspace. Editors M. Smith and P. Kollock (London: Routledge), 220-239.

Kollock, P. (1994). The Emergence of Exchange Structures: An Experimental Study of Uncertainty, Commitment, and Trust. Am. J. Sociol. 100 (2), 313-345. doi:10.1086/230539

Kraut, R. E., and Resnick, P. (2012). Building Successful Online Communities: Evidence-Based Social Design. Mit Press.

Kuhn, K. M., and Galloway, T. L. (2015). With a Little Help from My Competitors: Peer Networking Among Artisan Entrepreneurs. Entrepreneurship Theor. Pract. 39 (3), 571-600. doi:10.1111/etap.12053

Lakhani, K. R., and von Hippel, E. (2003). How Open Source Software Works: "free" User-To-User Assistance. Res. Pol. 32 (6), 923-943. doi:10.1016/s00487333(02)00095-1

Lamont, M., and Molnár, V. (2002). The Study of Boundaries in the Social Sciences. Annu. Rev. Sociol. 28, 167-195. doi:10.1146/annurev.soc.28.110601.141107

Lampe, C., and Johnston, E. (2005). "Follow the (Slash) Dot: Effects of Feedback on New Members in an Online Community," in Proceedings of the 2005 International ACM SIGGROUP Conference on Supporting Group Work (GROUP '05) (New York, NY: Association for Computing Machinery), 11-20. doi:10.1145/1099203.1099206

Langley, A., Lindberg, K., Mørk, B. E., Nicolini, D., Raviola, E., and Walter, L. (2019). Boundary Work Among Groups, Occupations, and Organizations: From Cartography to Process. Annals 13 (2), 704-736. doi:10.5465/ annals.2017.0089

Lave, J., and Wenger, E. (1991). Situated Learning: Legitimate Peripheral Participation. Cambridge University Press.

Lawler, E. J. (2010). "Relational Cohesion Theory [Electronic Version]," in Encyclopedia of Group Processes \& Intergroup Relations. Editors J. M. Levine and M. A. Hogg (Thousand Oaks, CA: Sage Publications), 690-691. doi:10.4135/9781412972017.n211

Lawler, E. J., Thye, S. R., and Yoon, J. (2000). Emotion and Group Cohesion in Productive Exchange. Am. J. Sociol. 106 (3), 616-657. doi:10.1086/318965

Lawler, E. J., and Yoon, J. (1996). Commitment in Exchange Relations: Test of a Theory of Relational Cohesion. Am. Sociological Rev. 61, 89-108. doi:10.2307/ 2096408

Lawler, E. J., and Yoon, J. (1998). Network Structure and Emotion in Exchange Relations. Am. Sociological Rev. 63, 871-894. doi:10.2307/2657506

Lee, G. K., and Cole, R. E. (2003). From a Firm-Based to a Community-Based Model of Knowledge Creation: The Case of the Linux Kernel Development. Organ. Sci. 14 (6), 633-649. doi:10.1287/orsc.14.6.633.24866

Lerner, J., and Tirole, J. (2002). Some Simple Economics of Open Source. J. Ind. Econ. 50 (2), 197-234.

Lewin, K. (1947). Frontiers in Group Dynamics. Hum. Relations 1 (2), 143-153. doi:10.1177/001872674700100201

Ley, B. L. (2007). Vive les roses!: The architecture of commitment in an online pregnancy and mothering group. J. Computer-Mediated Commun. 12 (4), 1388-1408. doi:10.1111/j.1083-6101.2007.00378.x

Lin, N. (1999). Building a Network Theory of Social Capital. Connections 22, 28-51. doi:10.1108/14691930410550381
Lin, N., Cook, K., and Burt, R. S. (2001). Social Capital: Theory and Research. NY: Taylor \& Francis.

Lovaglia, M. J. (1995). Power and Status. Small Group Res. 26 (3), 400-426. doi:10.1177/1046496495263005

Lovaglia, M. J. (1994). Relating Power to Status. Adv. Group Process. 11, 87-111. Mackert, J. (2014). Social Closure. New York: Oxford Bibliographies.

Mantere, S., Aula, P., Schildt, H., and Vaara, E. (2013). Narrative Attributions of Entrepreneurial Failure. J. Business Venturing 28, 459-473. doi:10.1016/ j.jbusvent.2012.12.001

Markovsky, B., Willer, D., and Patton, T. (1988). Power Relations in Exchange Networks. Am. Sociol. Rev. 53, 220-236. doi:10.2307/2095689

Marquis, C., Lounsbury, M., and Greenwood, R. (2011). "Community as an Institutional Order and a Type of Organizing," in Research in the Sociology of Organizations (Bingley, United Kingdom: Emerald Group Publishing).

Merton, R. K. (1973). The Sociology of Science: Theoretical and Empirical Investigations. University of Chicago press.

Molm, L. D., and Cook, K. S. (1995). Social Exchange and Exchange Networks. Sociological Perspect. Soc. Psychol. 2 (3), 209-235.

Oldham, S., Fulcher, B., Parkes, L., Arnatkevic Iütè, A., Suo, C., and Fornito, A. (2019). Consistency and Differences between Centrality Measures across Distinct Classes of Networks. PLOS ONE 14 (7), e0220061. doi:10.1371/ journal.pone.0220061

O'Mahony, S., and Ferraro, F. (2007). The Emergence of Governance in an Open Source Community. Acad. Manag. J 50 (5), 1079-1106.

O'Mahony, S., and Lakhani, K. R. (2011). Organizations in the Shadow of Communities. Emerald Group Publishing Limited.

Oppermann, K., and Spencer, A. (2016). Telling Stories of Failure: Narrative Constructions of Foreign Policy Fiascos. J. Eur. Public Pol. 23 (5), 685-701. doi:10.1080/13501763.2015.1127272

Orbuch, T. L. (1997). People's Accounts Count: The Sociology of Accounts. Annu. Rev. Sociol. 23, 455-478. doi:10.1146/annurev.soc.23.1.455

Oz, T., Havens, R., and Bisgin, H. (2018). Assessment of Blame and Responsibility through Social Media in Disaster Recovery in the Case of \#FlintWaterCrisis. Front. Commun. 3, 45. doi:10.3389/fcomm.2018.00045

Parigi, P., Santana, J. J., and Cook, K. S. (2017). Online Field Experiments. Soc. Psychol. Q. 80 (1), 1-19. doi:10.1177/0190272516680842

Perry, B. L., Pescosolido, B. A., and Borgatti, S. P. (2018). Egocentric Network Analysis. Cambridge University Press.

Philips, D. J., and Zuckerman, E. W. (2001). Middle-Status Conformity: Theoretical Restatement and Empirical Demonstration in Two Markets. AJS 107, 379-429.

Podolny, J. M. (2008). Status Signals. Princeton University Press.

Porter, M. F. (1980). An Algorithm for Suffix Stripping. Program 14 (3), 130-137. doi:10.1108/eb046814

Powell, W. W., Koput, K. W., and Smith-Doerr, L. (1996). Interorganizational Collaboration and the Locus of Innovation: Networks of Learning in Biotechnology. Administrative Sci. Q. 41 (1), 116-145. doi:10.2307/2393988

Powell, W. W. (1990). "Neither market Nor Hierarchy: Network Forms of Organization," in Research in Organizational Behavior. Editors L. L. Cummings and B. M. Staw (Greenwich, CT: JAI Press), 295-336.

Preece, J., Nonnecke, B., and Andrews, D. (2004). The Top Five Reasons for Lurking: Improving Community Experiences for Everyone. Comput. Hum. Behav. 20 (2), 201-223. doi:10.1016/j.chb.2003.10.015

Putnam, R. D. (1995). Bowling Alone Revisited. The Responsive Community 1, $18-33$.

Putnam, R. D. (1993). Making Democracy Work: Civic Traditions in Modern Italy. N. J: Princeton.

Rainie, H., and Wellman, B. (2012). Networked: The New Social Operating System (Vol. 419). Mit Press.

Rheingold, H. (1993). The Virtual Community: Finding Commection in a Computerized World. Addison-Wesley Longman Publishing Co., Inc.

Rinker, T. W. (2020). Qdap: Quantitative Discourse Analysis Package. Available at: https://github.com/trinker/qdap.

Rosenkopf, L., and Nerkar, A. (2001). Beyond Local Search: Boundary-Spanning, Exploration, and Impact in the Optical Disk Industry. Strat. Mgmt. J. 22 (4), 287-306. doi:10.1002/smj.160

Safadi, H., Johnson, S. L., and Faraj, S. (2020). Who Contributes Knowledge? CorePeriphery Tension in Online Innovation Communities. Organizat. Sci. 32 (3), $752-775$. 
Schaefer, D. R., and Kornienko, O. (2009). Building Cohesion in Positively Connected Exchange Networks. Soc. Psychol. Q. 72 (4), 384-402. doi:10.1177/019027250907200409

Schaefer, D. R. (2011). Resource Characteristics in Social Exchange Networks: Implications for Positional Advantage. Soc. Networks 33 (2), 143-151. doi:10.1016/j.socnet.2010.12.002

Scherer, K. R. (1984). On the Nature and Function of Emotion: A Component Process Approach. Approaches Emot. 2293 (317), 31.

Schwalbe, M., Godwin, S., Holden, D., Schrock, D., Thompson, S., and Wolkomir, M. (2000). Generic Processes in the Reproduction of Inequality: An Interactionist Analysis. Social Forces 79 (2), 419-452. doi: $10.2307 / 2675505$

Shaw, A. (2012). Centralized and Decentralized Gatekeeping in an Open Online Collective. Polit. Soc. 40 (3), 349-388. doi:10.1177/0032329212449009

Sherif, M. (1954). Experimental Study of Positive and Negative Intergroup Attitudes between Experimentally Produced Groups: Robbers Cave Study. Norman, OK: University of Oklahoma.

Sherif, M., Harvey, O. J., White, B. J., Hood, W. R., and Sherif, C. W. (1961). Intergroup Conflict and Cooperation: The Robbers Cave experiment (Vol. 10). Norman, OK: University Book Exchange.

Sherif, M. (1958). Superordinate Goals in the Reduction of Intergroup Conflict. Am. J. Sociol. 63, 349-356. doi:10.1086/222258

Shifflett, S. (2001). Traders Who Launched GameStop Frenzy Are Turning against New Members. The Wall Street Journal. Available at: https://www.wsj.com/ articles/traders-who-launched-gamestop-frenzy-are-turning-against-newmembers-11612297756.

Silva, L., Goel, L., and Mousavidin, E. (2009). Exploring the Dynamics of Blog Communities: The Case of MetaFilter. Inf. Syst. J. 19 (1), 55-81. doi:10.1111/ j.1365-2575.2008.00304.x

Smithson, J., Sharkey, S., Hewis, E., Jones, R. B., Emmens, T., Ford, T., et al. (2011). Membership and Boundary Maintenance on an Online Self-Harm Forum. Qual. Health Res. 21 (11), 1567-1575. doi:10.1177/1049732311413784

Snow, D. A., and Anderson, L. (1987). Identity Work Among the Homeless: The Verbal Construction and Avowal of Personal Identities. Am. J. Sociol. 92 (6), 1336-1371. doi:10.1086/228668

Sproull, L., and Arriaga, M. (2007). "Online Communities," in Handbook of Computer Networks (Vol. 3). Editor H. Bidogli (John Wiley \& Sons).

Starr, P. (1982). The Social Transformation of American Medicine. Basic Books.

Stets, J. E., and Burke, P. J. (2005). "New Directions in Identity Control Theory," in Social Identification in Groups (Emerald Group Publishing Limited), 43-64.

Stinchcombe, A. L. (1965). Organizations and Social Structure. Handbook of organizations 44 (2), 142-193.

Sutanto, J., Tan, C.-H., Battistini, B., and Phang, C. W. (2011). Emergent Leadership in Virtual Collaboration Settings: A Social Network Analysis Approach. Long Range Plann. 44 (5-6), 421-439. doi:10.1016/j.lrp.2011.09.001

Tajfel, H., and Turner, J. C. (1985). "The Social Identity Theory of Intergroup Behaviour," in Psychology of Intergroup Relations. Editors S. Worchel and W. G. Austin. 2nd ed. (Springer), 7-24.

Thye, S. R. (2000). A Status Value Theory of Power in Exchange Relations. Am. Sociological Rev. 65 (3), 407-432. doi:10.2307/2657464

Thye, S. R., Lovaglia, M. J., and Markovsky, B. (1997). Responses to Social Exchange and Social Exclusion in Networks. Soc. Forces 75 (3), 1031-1047. doi:10.1093/sf/75.3.1031

Thye, S. R., Willer, D., and Markovsky, B. (2006). From Status to Power: New Models at the Intersection of Two Theories. Soc. Forces 84 (3), 1471-1495. doi:10.1353/sof.2006.0070

Thye, S. R., Yoon, J., and Lawler, E. J. (2002). "The Theory of Relational Cohesion: Review of a Research Program Research Program," in Advances in Group Processes (IEEE).

Tonnies, F., and Loomis, C. P. (1957). Community and Society. North Chelmsford, MA: Courier Corporation.

Uzzi, B. (1999). Embeddedness in the Making of Financial Capital: How Social Relations and Networks Benefit Firms Seeking Financing. Am. Sociological Rev. 64 (4), 481-505. doi:10.2307/2657252
Uzzi, B. (1997). Social Structure and Competition in Interfirm Networks: The Paradox of Embeddedness. Administrative Sci. Q. 42, 35-67. doi:10.2307/ 2393808

Vaisey, S. (2007). Structure, Culture, and Community: The Search for Belonging in 50 Urban Communes. Am. Sociol. Rev. 72 (6), 851-873. doi:10.1177/ 000312240707200601

Vedres, B., and Stark, D. (2010). Structural Folds: Generative Disruption in Overlapping Groups. Am. J. Sociol. 115 (4), 1150-1190. doi:10.1086/ 649497

Walker, H. A., Thye, S. R., Simpson, B., Lovaglia, M. J., Willer, D., and Markovsky, B. (2000). Network Exchange Theory: Recent Developments and New Directions. Soc. Psychol. Q. 63 (4), 324-337. doi:10.2307/2695843

Wang, Y., Croucher, S., and Pearson, E. (2021). National Leaders' Usage of Twitter in Response to COVID-19: A Sentiment Analysis. Front. Commun. 1, 183.

Wasko, M. M., and Faraj, S. (2005). Why Should I Share? Examining Social Capital and Knowledge Contribution in Electronic Networks of Practice. MIS Q. 29, 35-57. doi:10.2307/25148667

Wasko, M. M., and Faraj, S. (2000). "It Is what One Does": Why People Participate and Help Others in Electronic Communities of Practice. J. Strateg. Inf. Syst. 9, 2-3. doi:10.1016/s0963-8687(00)00045-7

Weber, M. (1921). Sociology of Community. Springer.

Weick, K. E., Sutcliffe, K. M., and Obstfeld, D. (2005). Organizing and the Process of Sensemaking. Organ. Sci. 16, 409-421. doi:10.1287/orsc.1050.0133

Wenger, E. (1998). Communities of Practice: Learning, Meaning, and Identity. Cambridge University Press.

West, R., Paskov, H. S., Leskovec, J., and Potts, C. (2014). Exploiting Social Network Structure for Person-To-Person Sentiment Analysis. Tacl 2, 297-310. doi:10.1162/tacl_a_00184

White, D. R., and Harary, F. (2001). The Cohesiveness of Blocks in Social Networks: Node Connectivity and Conditional Density. Sociological Methodol. 31 (1), 305-359. doi:10.1111/0081-1750.00098

Wicke, P., and Bolognesi, M. M. (2021). Covid-19 Discourse on Twitter: How the Topics, Sentiments, Subjectivity, and Figurative Frames Changed over Time. Front. Commun. 6, 45. doi:10.3389/fcomm.2021.651997

Widdicombe, S., and Wooffitt, R. (1990). 'Being' versus 'Doing' Punk: On Achieving Authenticity as a Member. J. Lang. Soc. Psychol. 9 (4), 257-277. doi:10.1177/0261927 x9094003

Yeshua-Katz, D. (2013). Couch Award Winner: Stigma Resistance in Online Communities. AoIR Selected Papers of Internet Research. Available at: https://journals.uic.edu/ojs/index.php/spir/article/view/8513.

Yeshua-Katz, D. (2016). Online Boundary Work in Stigmatized Groups: The Case of Support Groups for Israeli Childless Women. Int. J. Commun. $10,20$.

Zhang, J., and Centola, D. (2019). Social Networks and Health: New Developments in Diffusion, Online and Offline. Annu. Rev. Sociol. 45, 91-109. doi:10.1146/ annurev-soc-073117-041421

Conflict of Interest: The author declares that the research was conducted in the absence of any commercial or financial relationships that could be construed as a potential conflict of interest.

Publisher's Note: All claims expressed in this article are solely those of the authors and do not necessarily represent those of their affiliated organizations, or those of the publisher, the editors, and the reviewers. Any product that may be evaluated in this article, or claim that may be made by its manufacturer, is not guaranteed or endorsed by the publisher.

Copyright $\odot 2022$ Santana. This is an open-access article distributed under the terms of the Creative Commons Attribution License (CC BY). The use, distribution or reproduction in other forums is permitted, provided the original author(s) and the copyright owner(s) are credited and that the original publication in this journal is cited, in accordance with accepted academic practice. No use, distribution or reproduction is permitted which does not comply with these terms. 